\title{
Descending Control of Electroreception. I. Properties of Nucleus Praeeminentialis Neurons Projecting Indirectly to the Electrosensory Lateral Line Lobe
}

\author{
Joseph Bastian and Bradford Bratton \\ Department of Zoology, University of Oklahoma, Norman, Oklahoma 73019
}

The first-order CNS processing region within the electrosensory system, the electrosensory lateral line lobe, receives massive descending inputs from the nucleus praeeminentialis as well as the primary afferent projection. The $n$. praeeminentialis receives its input from the electrosensory lateral line lobe as well as from higher centers; hence this nucleus occupies an important position in a feedback loop within the electrosensory system. This report describes the physiological properties of a category of $\mathbf{n}$. praeeminentialis neurons characterized by very high spontaneous firing frequency, but relatively poor sensitivity to electrolocation targets as compared to neurons in the electrosensory lateral line lobe. These neurons are specialized to encode longterm changes in electric organ discharge amplitude with high resolution.

Intracellular recording and Lucifer yellow staining of these neurons show that they are the previously described multipolar neurons of the $\mathrm{n}$. praeeminentialis, and they project bilaterally to the posterior eminentia granularis. Posterior eminentia granularis efferents project to the electrosensory lateral line lobe forming its dorsal molecular layer. Hence, these multipolar cells influence the electrosensory lateral line lobe circuitry indirectly. The information that the multipolar cells encode regarding the electric organ discharge amplitude may be needed for a gain control mechanism operative within the electrosensory lateral line lobe. Previous studies have shown that the indirect projection from the $\mathbf{n}$. praeeminentialis to the electrosensory lateral line lobe must be intact for this gain control mechanism to operate.

Sensory processing systems usually employ extensive networks of descending or feedback connections which are thought to be important in controlling or modulating the charactcristics of neurons in their target areas. Descending control could impart considerable flexibility or adaptability to a sensory system, allowing, for example, control of the sensitivity or gain of the system, control of receptive field size, and modulation of various dynamic features of a neuron's responses. The electrosensory system of weakly electric fish is rapidly becoming one of the most thoroughly studied vertebrate sensory systems, and as in most other sensory systems, neuroanatomical studies show

Received Aug. 29, 1989; revised Oct. 27, 1989; accepted Nov. 7, 1989.

This work was supported by National Institutes of Health grant NS 12337 and OCAST contract 1669 to J.B.

Correspondence should be addressed to Dr. Joseph Bastian at the above address. Copyright (C) 1990 Society for Neuroscience $0270-6474 / 90 / 041226-15 \$ 02.00 / 0$ that major descending pathways exist (scc Carr and Malcr, 1986, for anatomical review). Relatively little information is available, however, concerning the functional characteristics of neurons contributing to these descending pathways.

Weakly electric fish generate an electric field around their body by means of an electric organ located in their tail, and the amplitude and phase of this electric organ discharge (EOD) field are continuously measured with electroreceptors scattered over the surface of the fish. Objects in the environment having impedances different from that of the water distort this field, causing amplitude and phase modulations. These EOD distortions cause changes in the firing frequency and timing of electroreceptor afferents which terminate somatotopically within the electrosensory lateral line lobe (ELL) (Carr et al., 1982; Heiligenberg and Dye, 1982). The ELL, a complex laminated structure, has been intensively studied anatomically (Réthelyi and Szabo, 1973; Maler ct al., 1974, 1981; Maler, 1979; Shumway, 1989b) and physiologically (Enger and Szabo, 1965; Bastian, 1981b; Saunders and Bastian, 1984; Mathieson and Maler, 1988; Shumway, 1989a; Shumway and Maler, 1989). The output of the ELL projects primarily contralaterally to the midbrain, terminating in the torus semicircularis and in an isthmic structure, the nucleus praeeminentialis pars dorsalis (NPd). The NPd, which also receives input from the torus semicircularis, projects bilaterally back to the ELLs forming a feedback loop between first- and second-order electrosensory processing stations. The NPd output forms 2 separate pathways and one of these, the tractus stratum fibrosum (TSF), projects directly to the ELL forming its ventral molecular layer. The second pathway, the praeeminential cerebellar tract (PECB), projects to the posterior eminentia granularis (EGP), which is a mass of cerebellar granule cells overlying the ELL. The parallel fiber output of the EGP forms the ELL's dorsal molecular layer. Hence, the NPd projects both directly and indirectly to the ELL. The neuroanatomical studies of Sas and Maler $(1983,1987)$ have not only provided the details of these afferent and efferent connections of the $n$. praeeminentialis, but have also provided descriptions of the morphology of the principal cell types found in this nucleus. Thus far there have been no physiological studies of the NPd of weakly electric fish; however, Tong (1982) has described the physiological properties of NPd neurons in catfish. Although these animals do not generate electric signals, they are electroreceptive and respond to weak low-frequency signals produced by animate as well as inanimate sources (see Finger, 1986; Kalmijn, 1974, for reviews).

Preliminary studies of the function of the NPd projection to the EGP showed that the sensitivity of ELL output neurons is 
affected by anesthetizing or ablating this descending connection (Bastian, 1986a, b). In normal fish the responses of ELL output neurons remain relatively constant even when EOD amplitude is changed by large amounts, but this response constancy is lost when the descending input to the EGP is interfered with. One of the roles suggested for the indirect projection from the NPd to the ELL is to optimize the sensitivity of the ELL output neurons when changes in the amplitude of the animal's discharge occur (Bastian, 1986b). Altered sensitivity at the level of the ELL could compensate for changes in the responses of the electroreceptor afferents due to changes in discharge amplitude. This compensation is expected to occur in the central nervous system (CNS) since no efferents are known to project to the electroreceptors. This control seems to be primarily mediated via inhibitory mechanisms since local microinjection of GABA antagonists causes changes in ELL physiology similar to those due to lesions of the descending input to the EGP (Shumway and Maler, 1989).

In this and in the following report (Bratton and Bastian, 1990) we describe the functional characteristics of NPd neurons that project to the ELLs via the indirect and direct pathways. The identity of various physiologically defined neuron types was determined by intracellular recording and Lucifer yellow staining.

\section{Materials and Methods}

The weakly electric fish Apteronotus leptorhynchus, the brown ghost knife fish, was used exclusively in these studies. Surgical techniques were the same as described earlier (Bastian, 1981a). The animals were suspended in a tank measuring $45 \times 45 \times 15 \mathrm{~cm}$ deep for extracellular recording experiments or in a smaller tank $30 \times 30 \times 7 \mathrm{~cm}$ deep for the intracellular experiments. The latter tank was mounted on a vibration isolation table. The animals were artificially respirated by a continuous flow of water over the gills, and water temperature and resistivity were held at $26-28^{\circ} \mathrm{C}$ and $10 \mathrm{k} \Omega \mathrm{cm}$, respectively.

The apteronotids have an electric organ derived from spinal motor neurons, hence their electric organ discharge remains normal despite the fact that the animals were immobilized with the curare-like drug gallamine triethiodide (Flaxedil). The discharge was measured via electrodes placed near the animal's head and tail, and this signal provided a time base or carrier signal for generating electrical stimuli used to modulate the fish's discharge amplitude. EOD amplitude was measured with a pair of silver wire electrodes separated by $1 \mathrm{~cm}$ and oriented perpendicular to the long axis of the fish just caudal to the operculum. In some experiments it was necessary to monitor the voltage across the fish's skin. This was measured between a wire electrode implanted in the dorsal musculature and a wire, insulated except at the tip, which was placed against the body wall just caudal to the pectoral fin.

Step changes in EOD amplitude were produced by adding or subtracting a second signal from the animal's discharge. This was a train of single cycles of a sinusoidal signal having a period slightly less than that of the EOD synchronized to the electric organ discharge waveform recorded between the head and tail of the fish. Electrical stimuli were isolated from ground via stimulus isolation transformers and were applied to the fish with electrodes mounted on the tank walls on either side of the fish, "transverse geometry," or with electrodes in the animal's mouth and at the tip of the tail, "symmetrical geometry." With the former, geometry current flow is inward through one side of the body and outward through the opposite side, and changes in EOD amplitude of opposite sign occur on opposite sides of the body. With symmetrical geometry, current flow is unidirectional around the perimeter of the fish; hence changes in EOD amplitude of the same sign occur over about the rostral $80 \%$ of the body surface. Stimulus amplitude was regulated with Hewlett Packard 350D step attenuators, and the unattenuated signal amplitude $(0 \mathrm{~dB})$ was set to $3.75 \mathrm{mV} / \mathrm{cm}$ rms without the fish in place. Sinusoidal amplitude modulations (AM) of the animals' electric organ discharges were also used as stimuli. These AMs were produced by multiplying the EOD waveform recorded between the head and tail by a second sinusoidal signal using an analog multiplier circuit. The resulting amplitude-modulated EOD waveform was then added to the fish's discharge as described above. The peak-to-peak amplitude of the sinusoidal AM was $2.0 \mathrm{mV} / \mathrm{cm}$.

Moving electrolocation targets, aluminum or Plexiglas cylinders 12.7 $\mathrm{mm}$ in diameter and $6 \mathrm{~cm}$ long, were also used as stimuli. These were oriented vertically and moved by a stepping motor system at about 4 $\mathrm{cm} / \mathrm{sec}$ parallel to the long axis of the fish at various lateral distances. The position of the moving target was fed to an on-line computer system along with responses of single neurons so that histograms of neural activity as a function of object position could be produced. Histogram bin width was 50 msec and typically 7 replicates of each movement cycle were averaged. These histograms were smoothed with a simple digital filter, which eliminated much of the random variation but did not significantly alter the shape of the responses to the targets (Bastian, 1981a). Averages are given \pm 1 STD error (SE).

Extracellular recordings were made with metal-filled micropipettes as described by Frank and Becker (1964). In order to identify the region of the brain studied, a small lesion, $25-50 \mu \mathrm{m}$ in diameter, was produced by passing high-frequency current through the recording electrode at the end of each extracellular experiment. Animals were perfused as described below and frozen sections were cut and counterstained with cresyl violet. Intracellular recordings were made with microelectrodes filled with a $10 \%$ solution of Lucifer yellow CH (Sigma) in $0.1 \mathrm{M} \mathrm{LiCl}$. Pipettes were pulled from thin-wall aluminosilicate glass and had an initial resistance in excess of $1000 \mathrm{M} \Omega$. These were beveled in a jet stream containing $0.05 \mu \mathrm{m}$ gamma alumina particles and had a final resistance of between 100 and $400 \mathrm{M} \Omega$. Intracellular data were recorded with an FM magnetic tape recorder (Hewlett Packard 3960, 15 ips) and later replayed for analysis. Dye was injected from the recording electrode with a bridge amplifier by using either a steady hyperpolarizing current, 250-500 pA, or a negatively DC offset sinewave, 0.5-1 nA p-p. Animals were perfused transcardially, within $30 \mathrm{~min}$ after filling a neuron, with heparinized Ringer's solution, followed by $4 \%$ paraformaldehyde in Ringer's, followed by $30 \%$ sucrose, $4 \%$ paraformaldehyde. Brains were mounted in gelatin and $60-\mu \mathrm{m}$ frozen sections were cut with a sliding microtome. Sections were viewed with a fluorescence microscope equipped with a low-light silicon-intensified television (SIT) camera. Images were recorded on videotape and later replayed so that single neurons could be reconstructed.

\section{Results}

Neuroanatomical studies have determined the details of the projection patterns of the electroreceptor afferents within the primary CNS electrosensory processing area, the electrosensory lateral line lobe (Carr et al., 1982; Heiligenberg and Dye, 1982; Mathieson et al., 1987). The cytology of this first-order processing station has been defined both at the light (Maler, 1979) and at the electron microscopic level (Maler et al., 1981), and the projections of the electrosensory lateral line lobe have been studied as well (Maler et al., 1982). These studies have pointed to the importance of the $n$. praeeminentialis as an electrosensory processing station. The NPd receives major projections from the ELL and from the torus semicircularis, and the output of this nucleus is the major source of descending inputs to the ELL. The neuroanatomical studies of Sas and Maler (1983, 1987) described the morphology of many of the cell types found within the $n$. praeeminentialis, and also determined the projection pattern for a subset of these. The principle connections among these structures are summarized in Figure 1. The NPd projects to the ELL via 2 distinct pathways, one direct and the other indirect. Axons of neurons that project directly to the ELL form the tractus stratum fibrosum and these axons terminate bilaterally within the ELL forming the ventral molecular layer (VML in Fig. $1 B$ ). The physiological and morphological characteristics of the main cell type projecting via this pathway, the stellate neuron, will be described in the following paper (Bratton and Bastian, 1990). The indirect descending projection from the NPd terminates in a mass of granule cells overlying the ELL, the posterior eminentia granularis. The axons of NPd neurons 
Figure 1. Anatomical relationship of the electrosensory lateral line lobe to the nucleus praeeminentialis $(A)$, and a simplified diagram of the neural circuitry of the electrosensory lateral line lobe $(B) . B P$, Basilar pyramidal cell; $C B$, cerebellum; $D F L$, deep fiber layer; $D M L$, dorsal molecular layer; $D N L$, deep nuclear layer; $E G P$, eminentia granularis posterior; $E G M$, eminentia granularis medialis; $E L L$, electrosensory lateral line lobe; $G R$, granule neuron; $G R L$, granule cell layer; $L C$, caudal lobe of the cerebellum; $L L$, lateral lemniscus; $N A L L$, nucleus of the anterior lateral line nerve; $N B P$, nonbasilar pyramidal cell; $N P$, nucleus praeeminentialis; $P E C B$, praeeminential-cerebellar tract; $P F$, parallel fiber; $P L L$, plexiform layer; $P O L Y$, polymorphic neuron; $P O L Y L$, polymorphic layer; RECEPTOR $A F F$., receptor afferents; TEO, optic tectum; TS, torus semicircularis; $T S F$, tractus stratum fibrosum; $V$, neuron of the ventral molecular layer; $V M L$, ventral molecular layer.

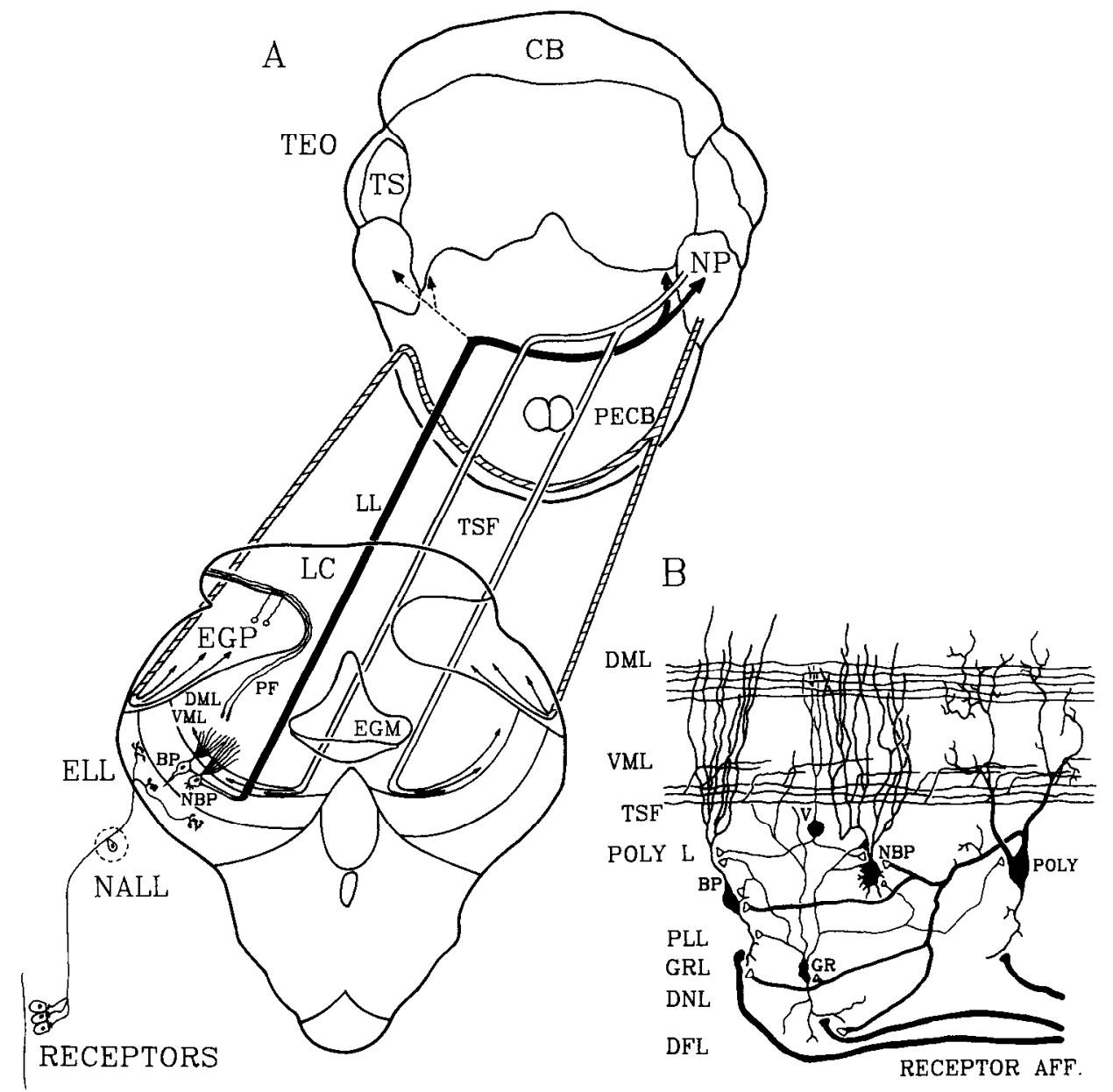

that project to the EGP form the praeeminential-cerebellar tract and also project bilaterally. The dorsal molecular layer of the ELL is composed of parallel fibers which are axons of the EGP granule cells; hence both NPd projections ultimately influence neurons within the ELL.

N. praeeminentialis neurons projecting to the EGP were usually found in clusters, more often in the caudal region of the nucleus, and the results of single cell labeling experiments show that morphologically distinct neuron types have similar, but not identical, physiological properties. The following physiological description is based on a sample of 27 cells studied in extracellular experiments. Intracellular marking of an additional 12 neurons having these same physiological properties shows that they correspond to the NPd multipolar cell described by Sas and Maler (1983).

\section{Spontaneous activity and responses to EOD amplitude modulations}

A characteristic feature of these NPd neurons is a very high spontaneous discharge rate ranging from 31.5 to 119.3 spikes/ sec, with a mean discharge frequency of $72.3 \pm 4.95$ recorded with extracellular electrodes. The interval histogram of Figure $2 A$ shows a bimodal distribution of spike intervals that was typical for these cells. The leftmost peak corresponds to a spike interval of about $2.5 \mathrm{msec}$ and the second broader component of the distribution is centered on an interval of about $15 \mathrm{msec}$. This bimodal distribution arises because the neurons have a tendency to fire 2 to several spikes in rapid succession. This firing behavior is also evident in the spontaneous activity shown in the raster displays of Figure $2, C, D$, which represent data from the same neuron as that of Figure $2 A$. Less often a unimodal interval histogram (Fig. $2 B$ ) was seen. This pattern of activity was observed in only one case in extracellular studies, but intracellular studies described later show that this more uniform pattern of activity is usually recorded from axon terminals within the NPd.

These NPd neurons respond to brief stepwise modulations in electric organ discharge amplitude with complex changes in frequency, as shown in Figure 2, $C-F$. Modulations of the EOD causing increased amplitude on the side of the body contralateral to the NPd recorded from and decreases in EOD amplitude ipsilaterally (Contra. Inc.), evoked an initial burst of spikes which adapted very rapidly. Time constants for this phase of the response averaged $4.4 \pm 0.47 \mathrm{msec}$ for stimulus amplitudes of $0.375 \mathrm{mV} / \mathrm{cm} \mathrm{rms}(-20 \mathrm{~dB})$. A pause in activity followed the initial burst, then the cells showed a secondary rise in firing frequency, and a brief pause in firing frequency usually followed the cessation of the stimulus. Responses to the opposite stimulus polarity, contralateral EOD decrease and ipsilateral increase, consisted of an inhibition of firing that often lasted for the duration of the stimulus. This was followed by a brief burst of activity at the cessation of the stimulus. Neurons that showed the same patterns of activity but in response to the opposite stimulus polarity were also seen. These respond to the contra- 
lateral increase with a decrease in activity identical to that of Figure $2 D$, and vice versa. The cells showing unimodal interval histograms responded similarly (Fig. 2, E, F). The latency of the response to the contralateral EOD increase averaged $5.7 \pm$ $0.41 \mathrm{msec}$, a value similar to the average latencies of 3.6 and $6.8 \mathrm{msec}$ for the 2 categories of ELL amplitude encoding neurons, basilar and nonbasilar pyramidal cells, or E- and I-cells (Bastian, 1981b).

Figure 3 summarizes the average responses of these neurons to a series of contralateral EOD increases of different amplitudes. The initial response, defined as the average spike frequency based on the first $10 \mathrm{msec}$ of the response period, increased approximately linearly with the $\log$ of stimulus amplitude up to about $1.2 \mathrm{mV} / \mathrm{cm} \mathrm{rms}$ (dashed line). Beyond this point the response saturated. Spike frequency determined over both the entire 100-msec response period (solid line) and the last $25 \mathrm{msec}$ of the response (dotted line) increased far less with increasing stimulus amplitude. Over the intermediate range of stimuli used, -20 to $-40 \mathrm{~dB}$, these response frequencies were less than the cells' average spontaneous firing rate (triangles) determined from the 100 - $\mathrm{msec}$ period preceding stimulation. These weak responses reflect the period of reduced activity, which becomes prolonged within this range of stimulus amplitudes, following the initial burst response. The initial highfrequency burst response of these neurons is similar to that seen when ELL E-cells are stimulated with a stepwise increase in EOD amplitude (Bastian, 1981b, 1986a, b; Shumway, 1989a), except that the NPd neurons' responses adapt much more rapidly. Adaptation time constants for the initial phase of the ELL cell responses averaged $24.4 \mathrm{msec}$ (Bastian, 1981b). Also, the ELL neurons do not typically show the suppression in activity following the initial burst; hence responses determined over the entire $100-\mathrm{msec}$ stimulation period increase linearly with the logarithm of stimulus amplitude (Bastian, 1986a). These NPd neurons are less able to encode the amplitude of brief changes in EOD amplitude than the ELL output neurons. Responses of these NPd neurons to stepwise stimuli presented with bilaterally symmetrical increases or decreases in EOD amplitude were also studied. Usually these were qualitatively the same as those described above.

These NPd neurons also responded to continuous sinusoidal amplitude modulations of the EOD, and 2 measures of the neurons' responses are plotted in Figure 4 as a function of AM frequency. Average spike frequency computed over the entire stimulus period (dashed line) did not change significantly until AM frequencies of at least $16 \mathrm{~Hz}$ were used. Amplitude modulation frequencies above this value increased spike rate about $50 \%$ from an average of approximately 60 to about 90 spikes/ sec. The second measure of the cells' responses, the maximum change in frequency within the AM cycle (solid line), is a measure of the degree of clustering of action potentials within each cycle. This measure increased rapidly with increasing AM frequency, reaching a peak at AMs of about $64 \mathrm{~Hz}$. These responses are similar to those of electroreceptor afferents and to the responses of many ELL basilar pyramidal cells, E-cells, which also

Figure 2. Spontaneous activity and responses to stepwise changes in EOD amplitude of NPd high-frequency neurons. $A, B$, Interval histograms of spontaneous activity recorded from 2 cells in the NPd. Mean frequencies based on $A$ and $B$ are 69.1 and 83.1 spikes/sec, respectively; 250 intervals are included in each histogram. $C, D$, Raster displays and
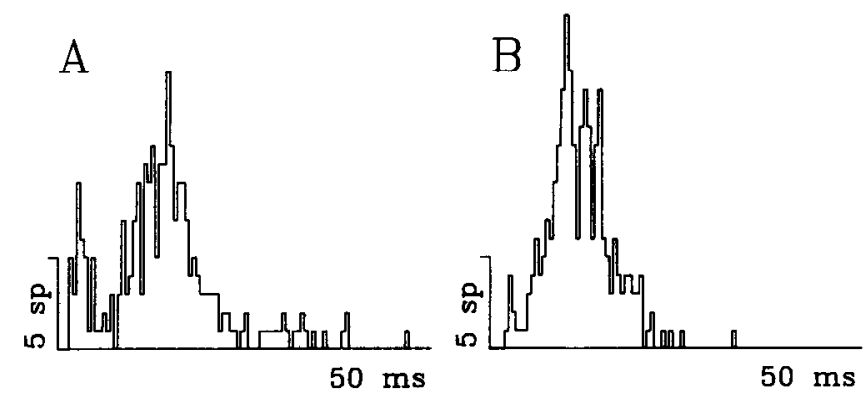

$$
\text { Contra. Inc. }
$$
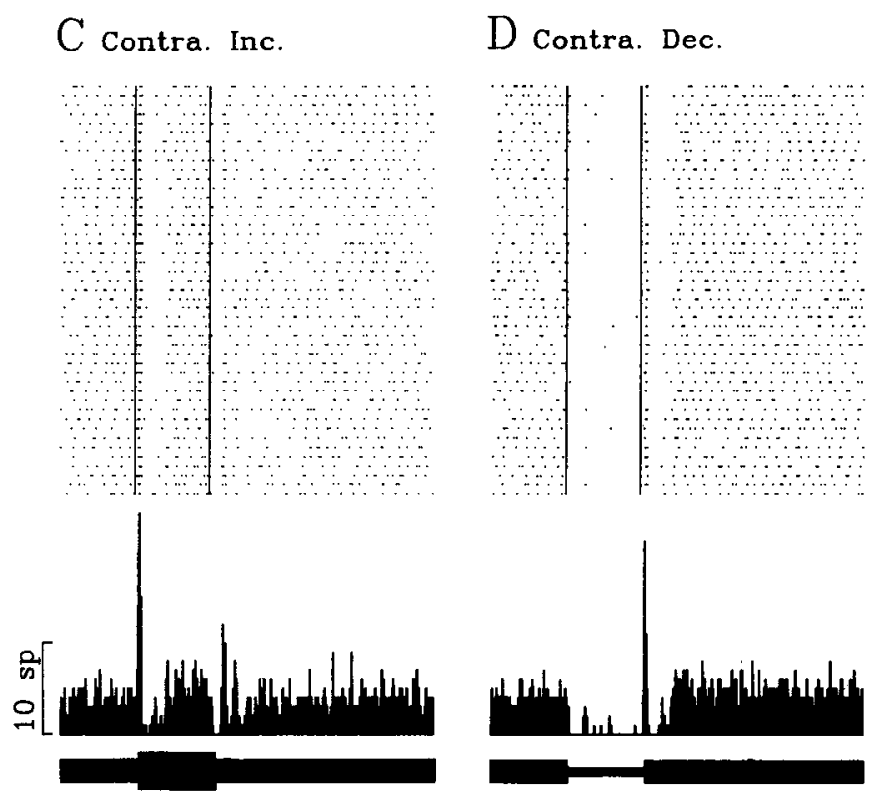

E contra. Inc.
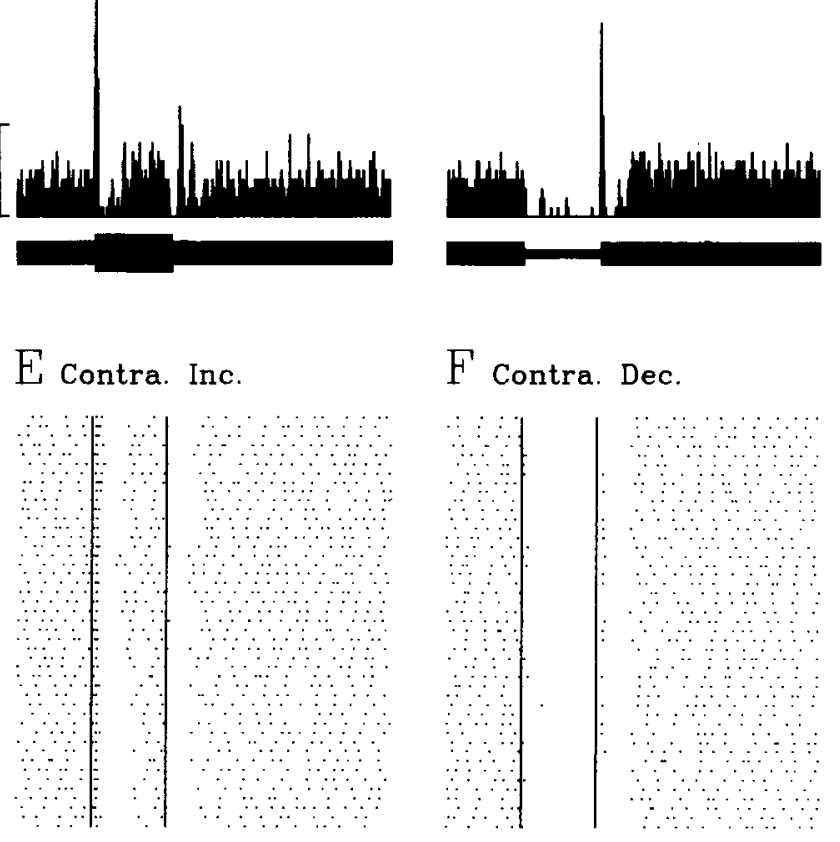

F Contra. Dec.
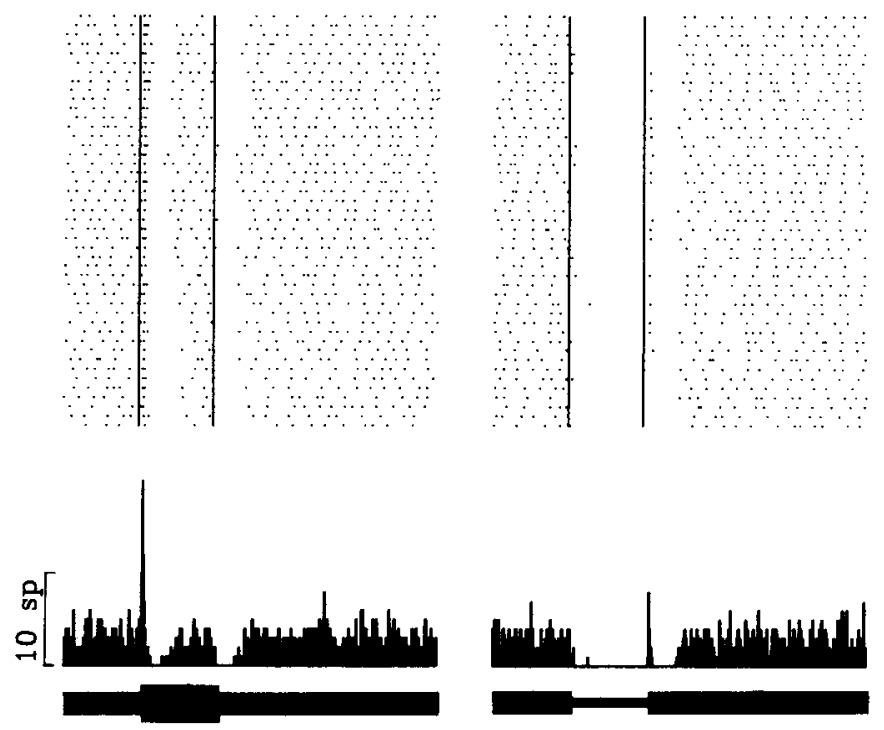

post-stimulus-time histograms (PSTH) of responses of the cell of $A$ to 45 presentations of $100 \mathrm{msec} 0.375 \mathrm{mV} / \mathrm{cm} \mathrm{rms}$ increases and decreases in EOD amplitude, respectively. Stimuli were presented transversely, hence Contra. Inc. refers to increased EOD amplitude contralateral to the recording site and Contra. Dec. refers to the opposite stimulus polarity. $E, F$, Raster displays and PSTHs of the cell of $B$ 's responses to these same stimuli. 


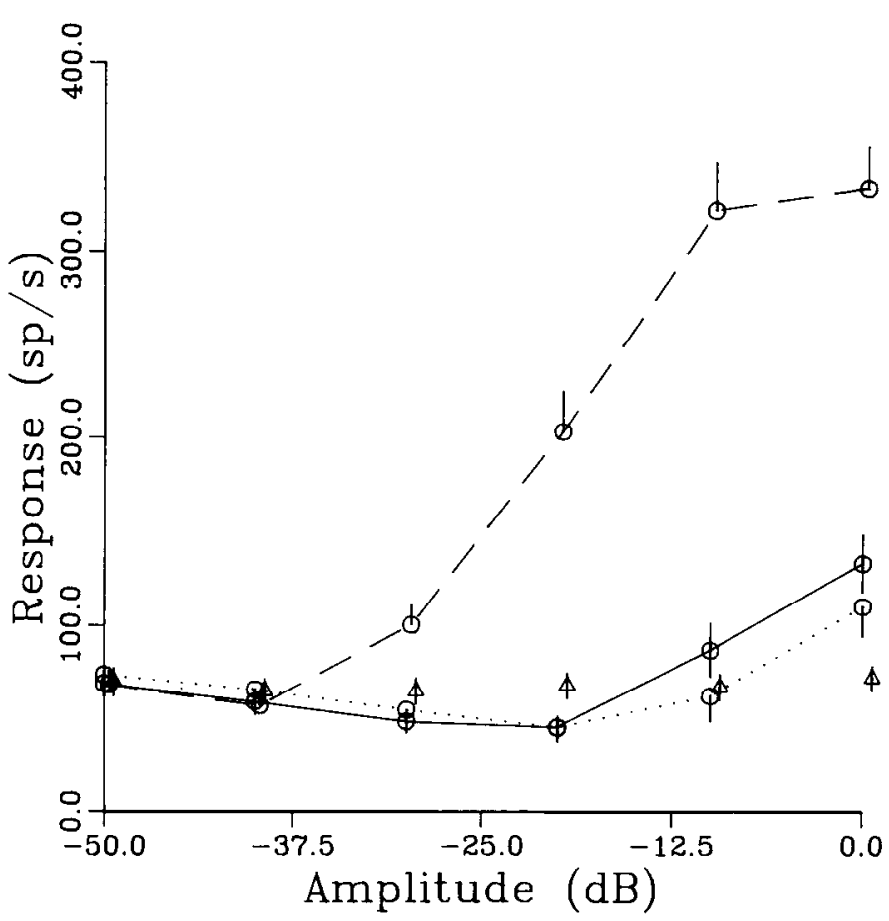

Figure 3. Average NPd multipolar neuron responses, $\pm 1 \mathrm{SE}$, to $100-$ msec contralateral increases in EOD amplitude of different magnitudes. Dashed line, Average frequency determined from the first $10 \mathrm{msec}$ of the response; solid line, average frequency computed over the 100 -msec stimulus period; dotted line, average frequency computed over the last $25 \mathrm{msec}$ of the stimulus period. Triangles show the average spontaneous frequency determined from the $100-\mathrm{msec}$ prestimulus period. Responses from 16 cells are included. Zero-dB response corresponds to an increment in EOD amplitude of $3.75 \mathrm{mV} / \mathrm{cm} \mathrm{rms.}$

show peak sensitivity to AMs of from 64 to $128 \mathrm{~Hz}$ (Bastian, $1981 \mathrm{a}, \mathrm{b})$. Subsets of ELL output neurons also show different AM frequency preferences; this property is related to a neuron's location in the different anatomical subdivisions of the ELL (Shumway, 1989a). These NPd neurons were also stimulated with low-frequency sinusoidal signals, ranging from 1 to $20 \mathrm{~Hz}$, in order to determine whether input received over the ampullary receptor system might contribute to their responses. They were insensitive to low-frequency stimuli at intensities as high as 3.75 $\mathrm{mV} / \mathrm{cm} \mathrm{rms}$.

\section{Responses to moving electrolocation targets}

The most consistent feature of the NPd high-frequency neurons' responses to moving targets is a large reduction in firing frequency due to a nonconducting (plastic) object moved parallel to the long axis of the fish contralateral to the recording site, as shown in Figure $5, A, B$. Of 22 neurons for which these data were available, 18 showed a response similar to this, 1 showed a similar response but it was caused by a conducting object, and the remaining 3 had virtually no response to the moving nonconducting target. The region of reduced firing frequency was usually bordered by a region of increased firing. This increase in activity occurred immediately following the reduction and was independent of target movement direction, suggesting that it represents a rebound effect.

These neurons also usually responded to conducting targets moved in the same manner (Fig. 5, $G, H$ ). These responses were also biphasic, and the position of the region of excitation caused

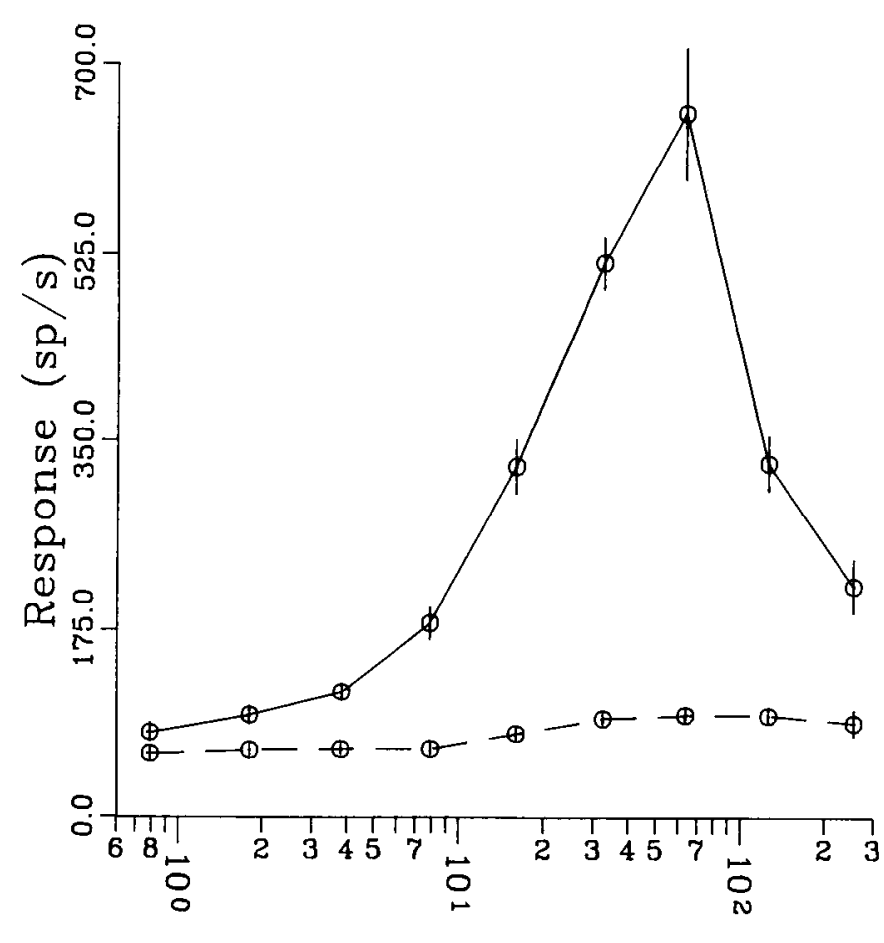

AM Frequency $(\mathrm{Hz})$

Figure 4. Average responses, $\pm 1 \mathrm{SE}$, of NPd multipolar neurons to sinusoidal amplitude modulation of the EOD field. Solid line, Average change in spike frequency within the AM cycle. This was computed as the peak frequency, based on 5 consecutive bins, minus the minimum frequency determined in the same way. The original data were accumulated in period histograms in which AM period was represented by 100 bins. Dashed line, Average spike frequency computed over the duration of stimulus presentation. Averages based on responses from 26 cells, except for AM frequencies of 128 and $256 \mathrm{~Hz}$, for which $n=4$.

by this type of object was well aligned with the region of reduced firing frequency causcd by the nonconductor. The sequence of the components of the response to the metal target reversed with opposite direction of movement in this and several other cases, as would be predicted for neurons having receptive fields consisting of bordering excitatory and inhibitory subdivisions.

Objects moved along the body ipsilateral to the recording site also usually evoked responses in these cells, as is shown in Figure $5, C, D$, and $I, J$. These responses were always weaker than those caused by the contralateral stimulus, and differences in response contingent on movement direction were often present. For example, this cell did not respond to an ipsilateral metal target moving in the tailward direction (Fig. 5I), but it did respond when the target moved headward (Fig. $5 J$ ). These responses suggest that the NPd high-frequency neurons may receive inputs from both the ipsilateral and contralateral ELLs, but an alternative explanation of these responses to ipsilateral targets is also possible. Neurons in the ELL also show wcak responses to objects moved along the side of the body opposite to that from which they receive receptor afferents. These responses probably do not represent a true bilateral input to the ELL since they persist even after the contralateral electrosensory inputs are removed by severing the ganglion of the anterior lateral line nerve (Bastian, 1986a). These weak ELL responses are probably caused by distortions of the EOD field ipsilateral 


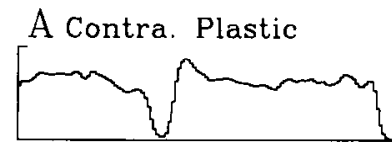

C Ipsi. Plastic
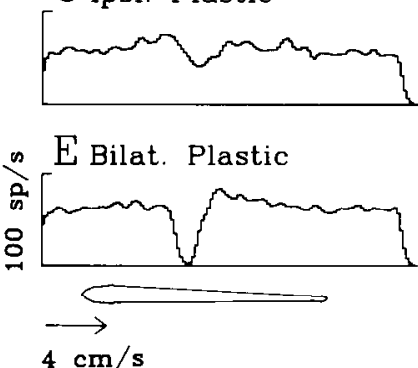

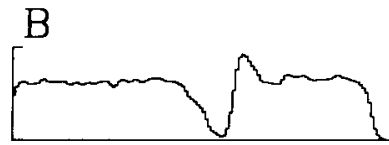

D
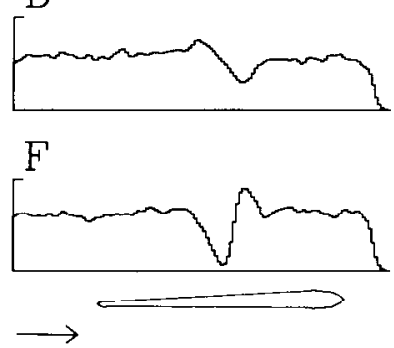

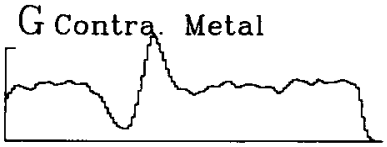

I Ipsi. Metal
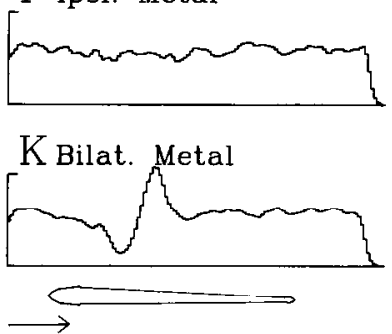

$\mathrm{H}$

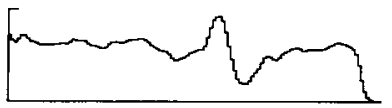

$\mathrm{J}$

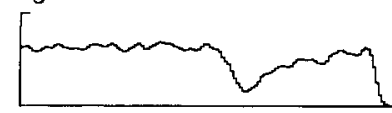

L

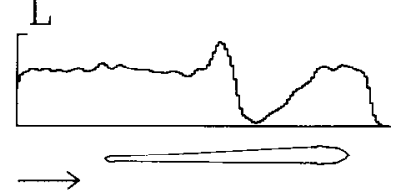

Figure 5. Responses of an NPd multipolar neuron to plastic $(A-F)$ and metal $(G-L)$ cylinders moved parallel to the long axis of the fish at a lateral distance of about $2.5 \mathrm{~mm}$. Arrows indicate movement direction relative to the outline of the fish, which is correctly scaled to the histogram length. Arrow length corresponds to $4 \mathrm{~cm}$, the distance traveled per second.

to the ELL recorded from due to the object moving close to the contralateral side of the body. This same phenomenon could account for the responses of NPd neurons to ipsilateral electrolocation targets. The NPd neurons were also studied using identical targets simultaneously moving bilaterally past the body. These responses were very similar to the responses to the contralateral target moving alone (Fig. $5, E, F, K, L$ ).

The targets were also moved parallel to the long axis of the fish at sequentially greater lateral distances in order to measure the electrolocation range of these neurons. The families of histograms of Figure 6 summarize the responses of an NPd highfrequency ncuron to a plastic target moving tailward and hcadward contralateral to the NPd (Fig. 6, $A, B$ ), ipsilateral to the NPd (Fig. 6, $C, D$ ), and Figure 6, $E, F$, shows the responses of this cell to the metal target moving contralaterally. The contours plotted near the outlines of the fish show the areas within which a given target caused increases ( + contours) and decreases (contours) in firing frequency of $20,40,60$, and $80 \%$ of the peak increase or decrease seen. Both the metal and plastic targets caused strong responses as long as the targets were moving near the animal, but the responses decayed rapidly as a function of target distance. Responses to targets moving on the ipsilateral side typically evoked significantly weaker responses, which also decayed rapidly as a function of distance.

Response magnitude was quantified by measuring the maximum change in spike frequency caused by the target at each distance lateral to the fish. The maximum change was equal to the peak increase above the spontaneous rate plus peak decrease, and each was determined from the mean of 5 consecutive bins. The calculations were made individually for both headward and tailward target movement, and individual cells did sometimes show directional differences. Data for both movement directions were, however, pooled since on the average directional differences were not significant. At larger target distances, where responses were no longer apparent, the analysis measured the random fluctuations in a cell's firing frequency which averaged about 20 spikes/sec.

The average changes in multipolar cell activity $(n=14)$ as a function of target distance from the contralateral side of the body are summarized in Figure $7 A$ (dotted lines) for metal $(+)$ and plastic $(\mathrm{x})$ targets. Clear-cut responses occur out to distances between 12.5 and $15 \mathrm{~mm}$ lateral to the fish. Beyond this distance the average random changes in firing frequency are as large as any changes in activity that may be evoked by the objects. The responses of 21 ELL basilar pyramidal neurons (E-cells) to the metal target moving ipsilaterally were measured in the same manner and are also shown (Fig. 7A, squares). Individual ELL neurons respond to objects as distant as $40 \mathrm{~mm}$ lateral to the fish and on the average show significant responses out to about $25 \mathrm{~mm}$. The NPd neurons seem less able to encode the presence of moving electrolocation targets than receptor afferents or ELL output neurons (Bastian, 1976, 1981a, b). The multipolar cells not only respond to moving targets over a shorter range lateral to the fish, but they also signal target position with less resolution than do the ELL neurons. Based on the slopes of the lines relating the cell's responses to target distance, ELL neurons will signal a given change in distance with a larger change in firing frequency. In addition to responding less well to electrolocation targets distant from the fish, as compared to ELL neurons, the responses of these NPd neurons are also smaller when the objects are close to the fish. Al a lateral distance of $2.5 \mathrm{~mm}$ the plastic and metal targets caused average changes in NPd high-frequency cell activity of 58 and 49 spikes/sec, respectively. This is approximately a $75 \%$ increase above the cells' average spontaneous firing frequency of 72 spikes/sec. At the same distance the ELL E-cells' average response was 87.9 spikes/sec, or an average increase of about $314 \%$ above the average spontaneous firing frequency of 28 spikes/sec.

Responses of $9 \mathrm{NPd}$ neurons to metal (+) and plastic (x) targets moved at various lateral distances past the fish ipsilateral to the NPd recorded from are summarized in Figure $7 B$. These responses were always much smaller than those caused by targets moved past the contralateral side of the body; the average changes in activity for targets moving at a distance of $2.5 \mathrm{~mm}$ were 29 and 31 spikes/sec for the plastic and metal targets, respectively, or about a $41 \%$ increase over the average spontaneous firing rate. The size of the responses to the electrolocation targets decreased to that of the random variations in firing very quickly, and objects 7-10 $\mathrm{mm}$ away from the ipsilateral side of the fish could not be unambiguously detected by these neurons.

Receptive field areas, regions of space lateral to the fish within which the metal and plastic targets evoked a given sized change in activity, were estimated by measuring the areas of contours such as those shown in Figure 6 . The $50 \%$ change in activity 
A Tailward Movement Contralateral Plastic
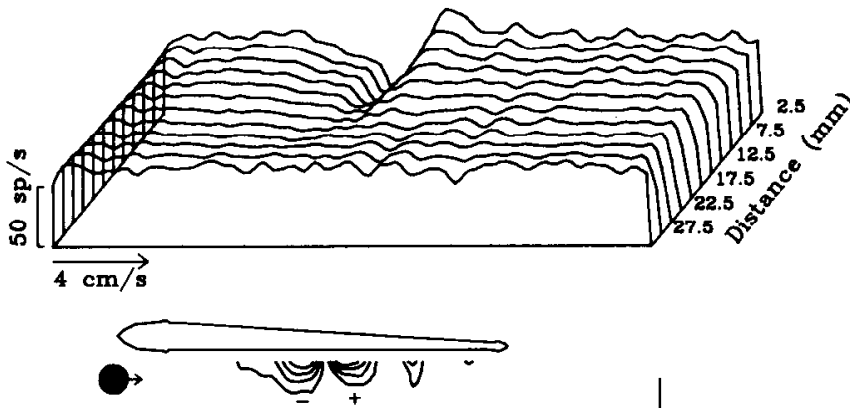

$$
\prod_{2 \mathrm{~cm}}
$$

C Tailward Movement Ipsilateral Plastic

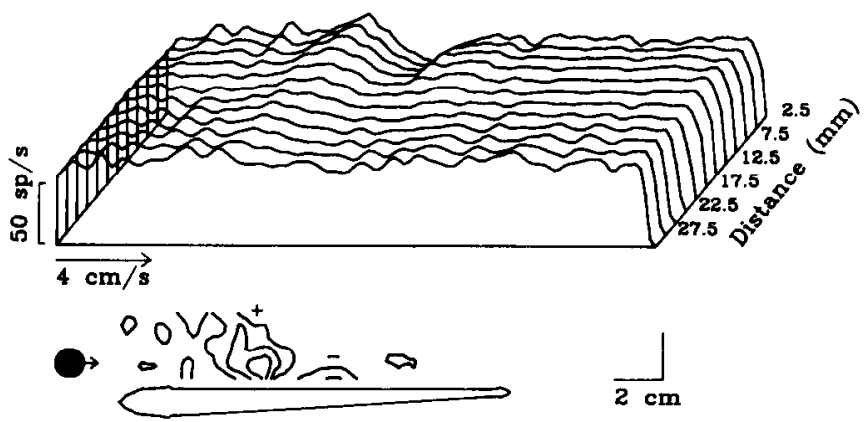

E Tailward Movement Contralateral Metal
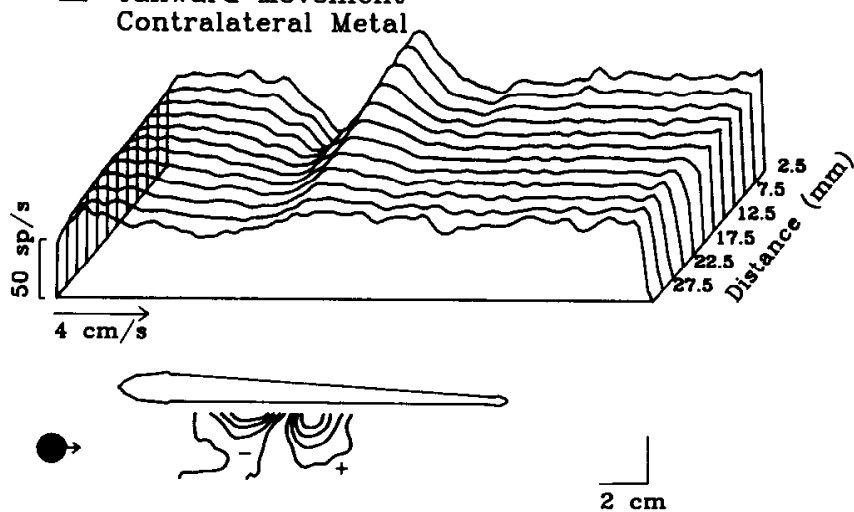

B Headward Movement Contralateral Plastic
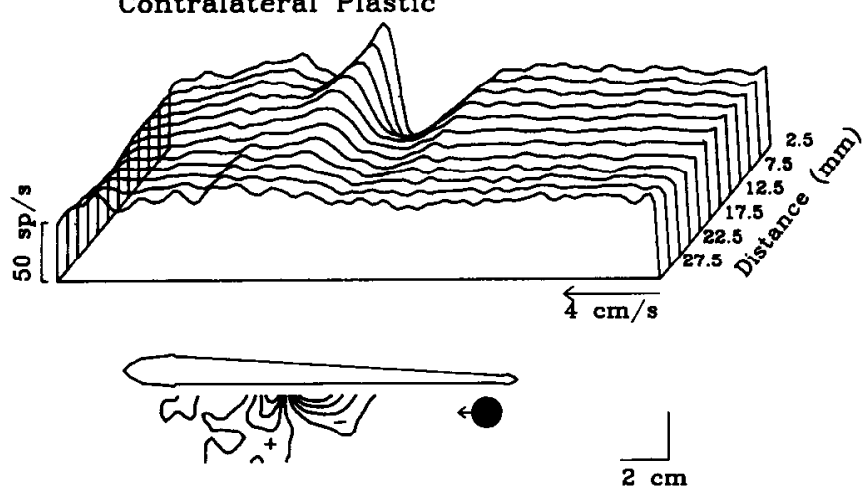

D Headward Movement Ipsilateral Plastic
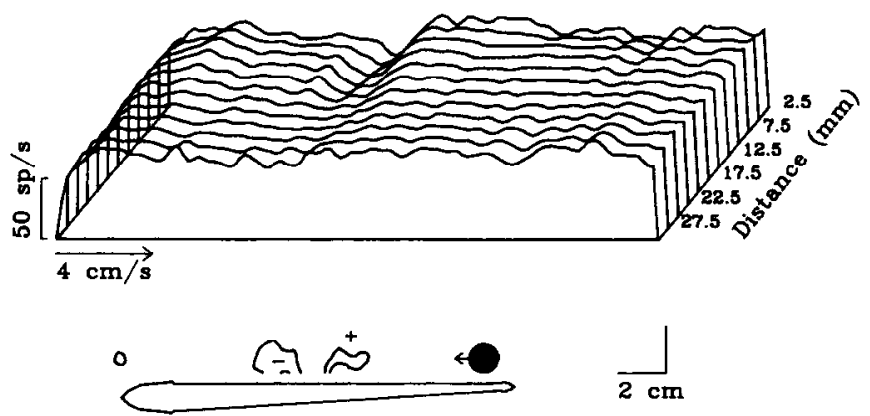

F Headward Movement Contralateral Metal
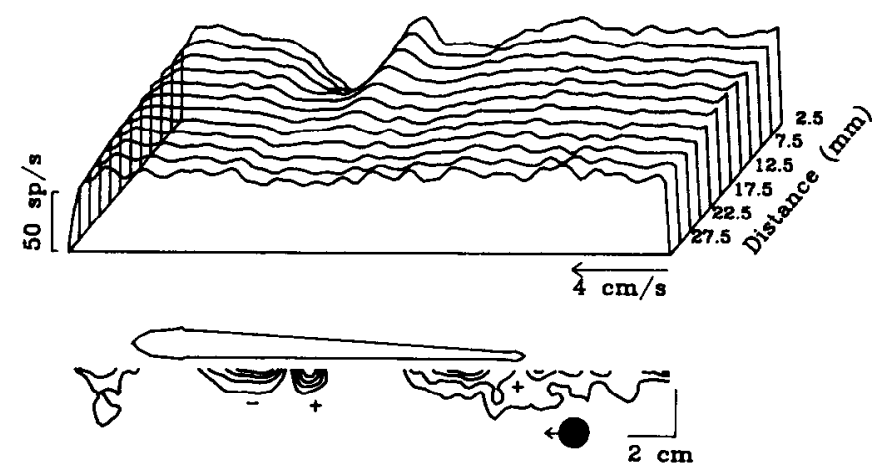

Figure 6. Responses of the cell of Figure 5 to a plastic cylinder moved along the fish at the indicated lateral distances contralateral $(A, B)$ and ipsilateral $(C, D)$ to the NPd recorded from. $E, F$, Responses of the same cell to a metal cylinder moved along the contralateral side of the fish. The contours near the outline of the fish show areas within which the moving electrolocation target evoked changes in activity of at least 20 , 40 , 60 , and $80 \%$ of the peak increase $(+)$ or maximum decrease $(-)$ in activity.

contours were chosen, and the increase contour was then that area within which the target caused a change at least as great as $50 \%$ of the maximum increase above the cell's spontaneous firing frcquency. The decreasc contour was based on $50 \%$ of the maximum decrease in spike frequency. Responses to ipsilateral as well as contralateral stimuli were analyzed, but the ipsilateral contours were based on $50 \%$ of the peak changes in activity evoked by the contralateral target so that comparisons of the ipsi- and contralateral responses were based on a common criterion.

No significant differences in the average areas of any receptive field component on a given side of the body were seen contingent on the target movement direction, although individual neurons did show such differences. No significant differences were seen among the avcrage arcas contingent on whether metal or plastic targets were used. Hence, data from experiments using different movement directions and target types were pooled. For targets moved along the fish contralateral to the NPd recorded from, the areas within which spike frequency increased were larger than those within which it decreased. The $50 \%$ increase contour averaged $215 \pm 35 \mathrm{~mm}^{2}$ and the area of the $50 \%$ decrease contour averaged $93 \pm 9 \mathrm{~mm}^{2}(p=0.001, t$ lest). No such 


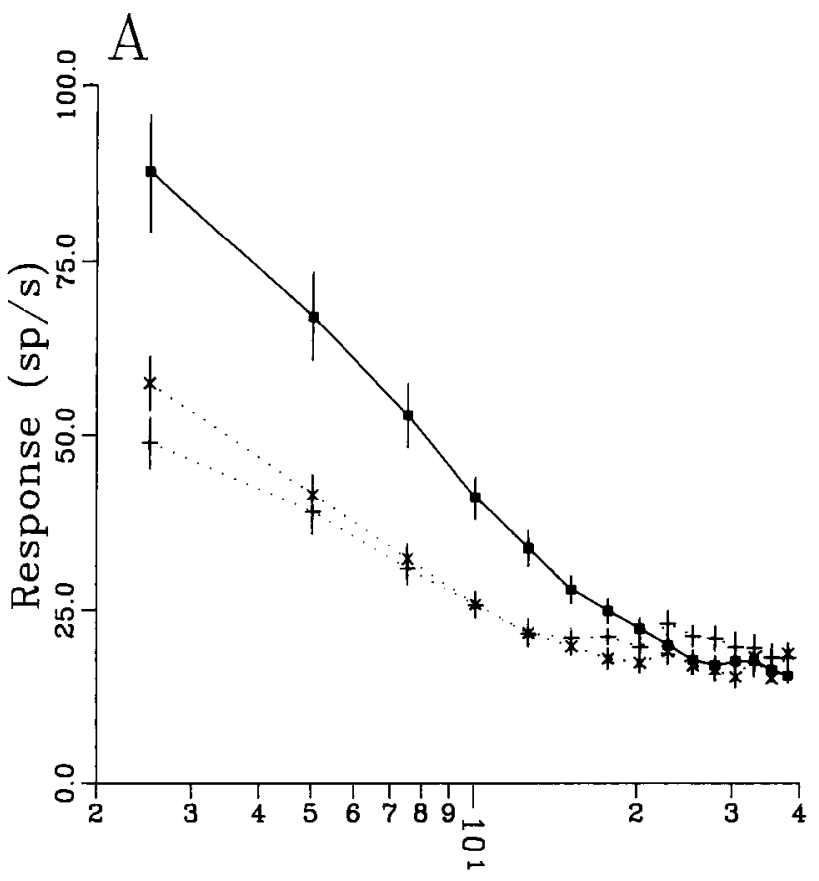

Target Distance (mm)

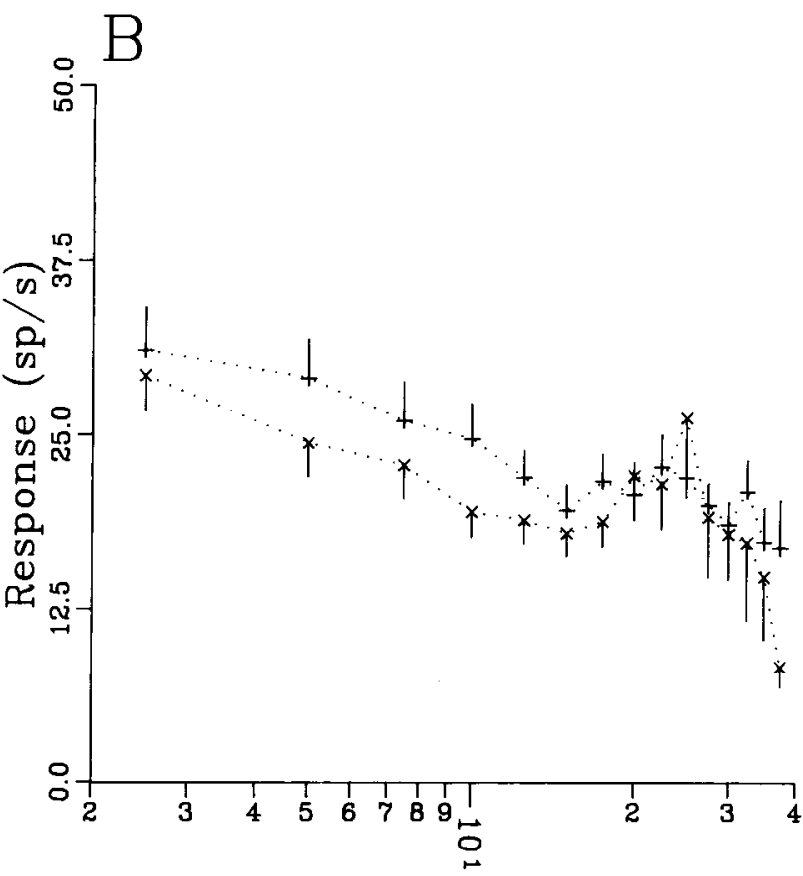

Target Distance $(\mathrm{mm})$

Figure 7. A, Average responses, $\pm 1 \mathrm{SE}$, of 14 multipolar neurons to metal $(+)$ and plastic $(\mathrm{x})$ targets moving at sequentially greater distances lateral to the fish contralateral to the recording site. Responses are equal to the peak increase in frequency plus the peak decrease seen at each target distance. Best-fit lines determined from responses to the targets at distances between 2.5 and $15 \mathrm{~mm}$ lateral to the fish are $y=76.6-21.6 \ln x$ and $y=64.4-16.5 \ln x$ for responses to plastic and metal, respectively. Squares show responses of 21 ELL basilar pyramidal cells to the moving metal target; best-fit line determined for responses to the target at distances between 2.5 and $25 \mathrm{~mm}$ lateral to the fish is $y=115.0-30.8 \mathrm{l} n x$. $B$, Average responses of multipolar cells to metal $(+)$ and plastic $(x)$ targets moving at sequentially greater lateral distances from the side of the fish ipsilateral to the NPd recorded from. Best-fit lines computed from responses to the target at distances between $2.5 \mathrm{and} 15 \mathrm{~mm}$ are $y=37.9$ $-6.22 \ln x$ and $y=35.0-6.42 \ln x$, respectively.

difference was seen for the receptive areas on the side ipsilateral to the NPd recorded from. The ipsilateral $50 \%$ increase and decrease contours averaged $62 \pm 29 \mathrm{~mm}^{2}$ and $73 \pm 27 \mathrm{~mm}^{2}$, respectively, and receptive field areas for the contralateral stimuli were significantly greater than for the ipsilateral stimuli. The total areas, $50 \%$ increase plus $50 \%$ decrease contours, averaged $308 \pm 34$ and $135 \pm 36 \mathrm{~mm}^{2}$ for the contralateral and ipsilateral stimuli, respectively ( $p=0.001, t$ test).

The responses of a sample of 21 ELL basilar pyramidal cells to the metal target moving ipsilaterally were also analyzed to determine receptive field areas. As in the case of the NPd cells, average headward and tailward responses were not different, but the areas of the $50 \%$ increase and decrease contours were, averaging $96 \pm 8$ and $247 \pm 22 \mathrm{~mm}^{2}$, respectively $(p<0.001, t$ test). The averages of the entire receptive field area, positive plus negative contours, were not different for the NPd and the ELL cells; these averaged $308 \pm 34$ and $343 \pm 24 \mathrm{~mm}^{2}$, respectively. However, the sizes of the excitatory and inhibitory components of the fields were different for these 2 cell types. In the case of the NPd cells, the excitatory portions of the receptive fields were significantly larger, while in the case of the ELL neurons, the inhibitory portions of the receptive fields were larger.

\section{Responses to prolonged changes in EOD amplitude}

The high-frequency NPd neurons showed a remarkable sensitivity to prolonged changes in EOD amplitude. This tonic response property has not been seen in any other central electro- sensory neurons and these cells may provide descending information necessary for gain control mechanisms operative at the level of the ELL. In these experiments EOD amplitude was changed by adding or subtracting a second field, single cycles of a sinusoidal signal synchronized to the electric organ discharge, from the animal's normal field. This technique alters the field amplitude uniformly over the length of the fish (Bastian, 1986b). This second field was applied to the animal with either transverse or symmetrical geometries, and the alterations in the EOD due to this stimulus were measured as changes in the net voltage drop across the animal's skin as described in Materials and Methods. A cell's firing frequency was calculated from the mean of interval histograms in which 250 spike intervals were accumulated. Spike frequency was usually measured after a delay of $30 \mathrm{sec}$ from the time at which EOD amplitude was altered, and measures of spike frequency made after much longer delays indicated that these responses were tonic.

The interval histograms of Figure 8 show examples of the changes that occur in response to prolonged alterations of EOD amplitude effected with transverse stimulus geometry. The normal transepidermal voltage for this fish was $2.58 \mathrm{mV} \mathrm{rms}$, and the histograms describing normal spontaneous activity, Figure $8, B, F$, had means of 14.0 and $15.1 \mathrm{msec}$ corresponding to average firing rates of 71.4 and $66.2 \mathrm{spikes} / \mathrm{sec}$, respectively. The histogram of Figure $8 \mathrm{~A}$ was produced $30 \mathrm{sec}$ after the EOD amplitude contralateral to the NPd studied was increased by $9 \%$ and this caused firing rate to increase to $92.1 \mathrm{spikes} / \mathrm{sec}$. Firing rate was 38.7 spikes/sec $30 \mathrm{sec}$ after EOD amplitude was 


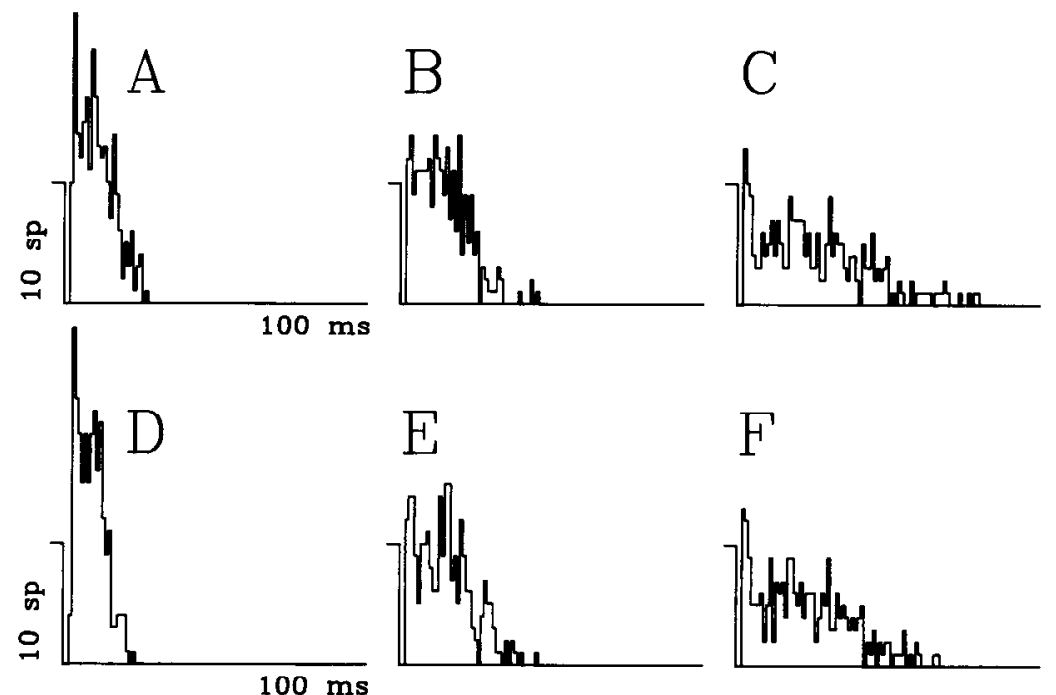

Figure 8. Responses of multipolar neurons to long-term changes in EOD amplitude. $A, C$, Interval histograms (250 spike intervals) produced $30 \mathrm{sec}$ after EOD amplitude was increased and decreased, respectively, by $9 \%$ contralateral to the recording site with transverse stimulus geometry. $B$, Interval histogram of the cells' spontaneous activity with the EOD at its normal amplitude. $D, F$, Interval histograms produced 4 min following the same EOD changes as in $A, C$. $E$, Interval histogram of spontaneous activity taken 30 $\mathrm{sec}$ after the EOD was returned to normal following a 4-min $9 \%$ change in amplitude. $G$, Mean $\pm 1 \mathrm{SE}$ of responses of 16 multipolar neurons to long-term changes in EOD amplitude. Solid line, Responses during transverse stimulus presentation; dashed line, responses with symmetrical stimulus geometry. Best-fit lines based on responses to EOD amplitude changes between $\pm 20 \%$ are $y-1.86+2.31 y$ and $y=-0.51+0.71 y$ for transverse and symmetrical stimulus geometries, respectively.

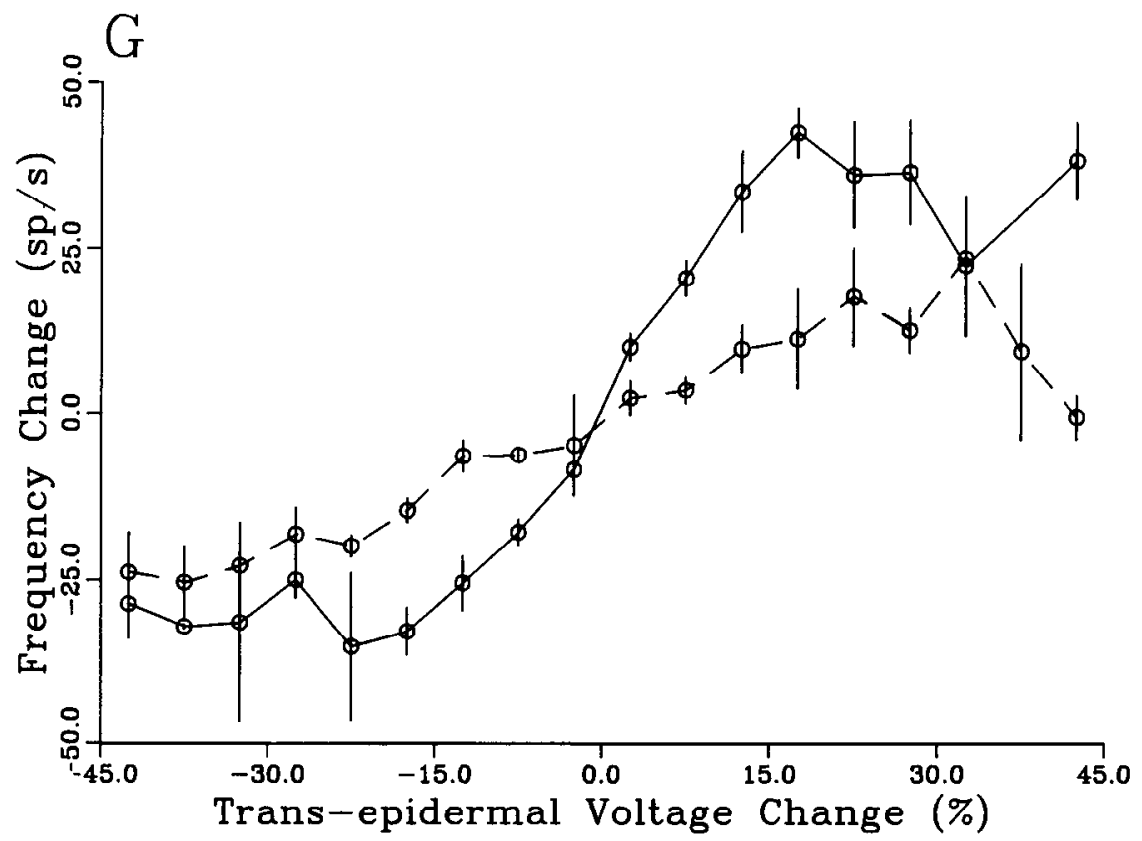

reduced by $9 \%$ (Fig. $8 \mathrm{C}$ ). The histograms were typically bimodal at low spike frequencies and the distribution of longer intervals was most affected by changes in EOD amplitude. The histograms of Figure $8, D$ and $F$, also show the changes in firing rate due to a $9 \%$ increase and decrease in EOD amplitude, respectively, but these data were acquired $4 \mathrm{~min}$ after EOD amplitude was changed. The average frequencies determined from these histograms were 106.0 and $43.8 \mathrm{spikes} / \mathrm{sec}$. The histogram of Figure $8 E$ was produccd $30 \mathrm{sec}$ after the termination of a 4-min alteration in EOD amplitude.

The responses of a sample of 16 high-frequency NPd neurons to prolonged changes in transepidermal voltage are summarized in Figure $8 G$. Changes in transepidermal voltage are expressed as percentages in order to normalize differences in individual discharge amplitudes. These neurons are more sensitive to changes in EOD amplitude due to transverse stimulus presen- tation (points connected by solid line) than to the equivalent changes caused by symmetrical stimulus presentation (dashed line). With transverse stimulation average activity is modulated over a range of about \pm 40 spikes/sec due to $\pm 20 \%$ changes in transepidermal voltage. Beyond this range of EOD amplitude changes spike frequency remains relatively constant. The slope of the best-fit line to the data between $+20 \%$ and $-20 \%$ changes in amplitude is 2.3 , and given an average normal transepidermal voltage of $2.7 \mathrm{mV} \mathrm{rms}$, this gives an increment in spike frequency of about 8.5 spikes/sec per $100 \mu \mathrm{V}$ rms change in EOD amplitude. The most sensitive neuron seen thus far responded to a $100-\mu \mathrm{V}$ change in EOD amplitude with a 17 spike/sec change in activity.

The symmetrical stimulus geometry was always less effective in altering the firing frequency of these neurons, as is shown in Figure $8 G$ (dashed line). The slope of the best-fit line to data 

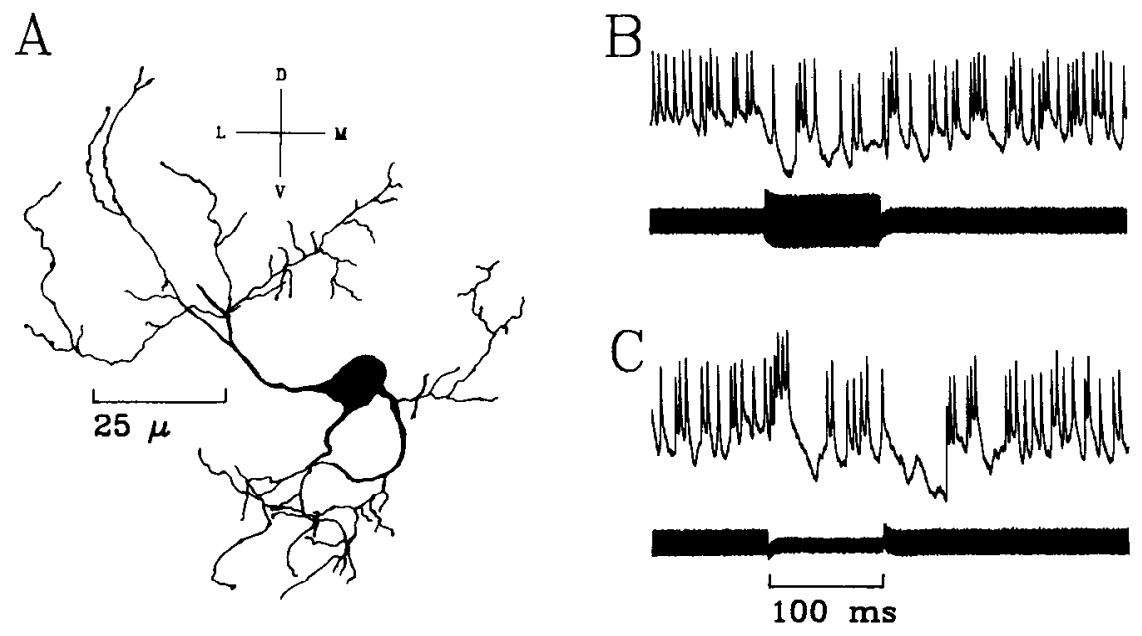

$\mathrm{D}$
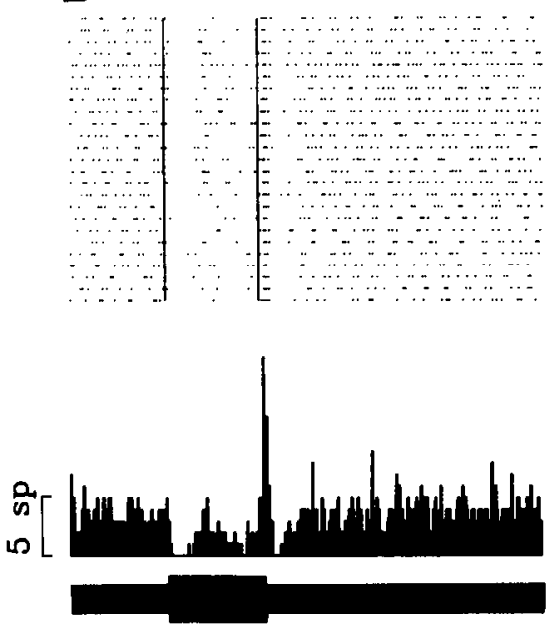

$\mathrm{E}$
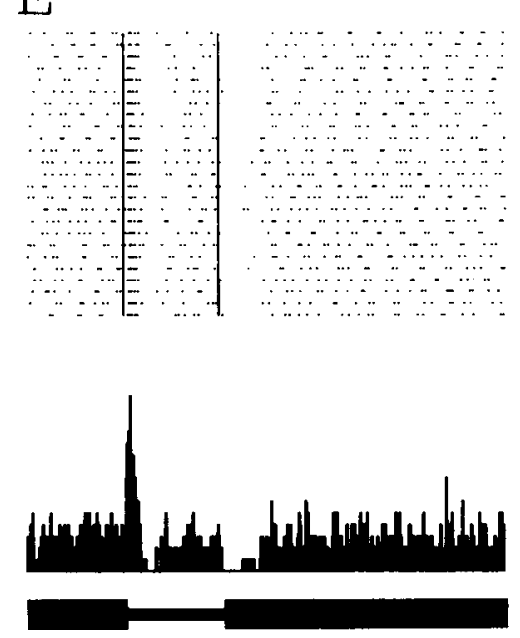

Figure 9. Anatomy and physiological properties of an NPd multipolar neuron. $A$, Reconstruction of a Lucifer yellow-filled multipolar neuron. $B, C$, Intracellular records showing this cell's responses to $0.375 \mathrm{mV} / \mathrm{cm} \mathrm{rms}$ increases and decreases in EOD amplitude, respectively. $C, D$, Raster displays and PSTHs of responses to 25 replicates of the stimuli of $B, C$. within the $\pm 20 \%$ interval is 0.71 , which gives an average increment in firing frequency of about 2.6 spikes/sec per $100-\mu \mathrm{V}$ change in transepidermal voltage. The difference between the responses due to transverse and symmetrical stimulus presentation is easily explained given the assumption that these neurons have bilateral receptive fields, and that the portion of the field contralateral to the NPd recorded from is predominantly excitatory while the ipsilateral field is predominantly inhibitory. The transverse stimuli, when causing a contralateral increase in transepidermal voltage coupled with ipsilateral decrease, would result in increased stimulation of the excitatory portion of the field and decreased stimulation of the inhibitory portion. Symmetrical stimuli causing changes of the same sign on both sides of the body would simultaneously drive both the excitatory and inhibitory portions of the field, resulting in less total excitatory input to the neuron. Cells were also seen that responded oppositely to the transverse stimulus compared to those shown in Figure 8 . These increased activity in response to contralateral decreases in EOD amplitude and decreased activity with contralateral increases. Examples of these are shown in the following section on intracellular experiments. These cells' responses were also weaker due to symmetrical changes in transepidermal volt- age, and they increased activity in response to symmetrical increases in EOD amplitude.

\section{Intracellular recording and identification of NPd high-frequency neurons}

The highly spontaneous neurons most often encountered in the intracellular experiments had a morphology similar to the multipolar ncurons described by Sas and Maler (1983). A partial reconstruction of a high-frequency neuron filled with Lucifer yellow is shown in Figure 9A. These cells usually had 3 main processes, 2 of which joined one end of the soma while the third joined near the opposite end. In all cases the axon of this cell type could be seen leaving the NPd at its caudal-lateral boundary where it entered the PECB tract. The axon branched immediately on entering this tract; one branch coursed caudally and in well-filled cases could be traced to its termination in the ipsilateral posterior eminentia granularis. The other branch ran ventrally in the portion of the PECB tract that crosses the midline before running caudally to the contralateral EGP. It was often difficult to determine exactly where the axon attached to the cell, but when it could be reconstructed, it connected either to one of the main processes or to the soma itself. Twelve neu- 
rons of this type were sufficiently filled with Lucifer yellow to allow at least partial reconstruction. Cell bodies were roughly ovoid in shape; the maximum diameter of these cells averaged $12.9 \pm 0.75 \mu \mathrm{m}$, and the length of the minor axis averaged 7.6 $\pm 0.49 \mu \mathrm{m}$. These dimensions are less than those given by Sas and Maler (1983) for this cell type, $36 \times 23 \mu \mathrm{m}$, and this is at least partially due to the considerable shrinkage that occurred with our fixation procedure.

These ncurons are very difficult to record from intracellularly. They frequently depolarized on impalement to the point that action potentials were no longer produced, and once they deteriorated to this state activity could rarely be restored even with significant hyperpolarizing current injection. The cell of Figure 9 had a spontaneous firing rate of 78 spikes/sec early in the recording session, but this increased to nearly 120 spikes/ sec within a few minutes. In 10 of the 12 neurons studied sufficient physiological data were acquired, and spontaneous firing frequency averaged $111.9 \pm 14 \mathrm{spikes} / \mathrm{sec}$. This value is higher than that seen with extracellular techniques and probably results from damage to the neurons. Figure $9, B, C$, shows intracellular records from this neuron during stimulation with transversely applied $100 \mathrm{~ms}, 375 \mu \mathrm{V} / \mathrm{cm}$ rms $(-20 \mathrm{~dB})$ changes in EOD amplitude. This neuron fired in bursts of 2 to several spikes, as seen in extracellular records, and these multiple discharges often originated from discrete depolarizations. Spontaneously occurring depolarizations of similar duration are seen in cases where the neuron has lost the ability to produce action potentials. This cell responded to increased EOD amplitude on the contralateral side of the body (Fig. 9B) with hyperpolarization and a pause in firing frequency which was followed by a burst of activity when the stimulus terminated. The responses to 25 presentations of this stimulus are shown in the raster display of Figure $9 D$. Responses to contralateral EOD decrease are shown in Figure $9, C, E$, and the sequence of events is approximately reversed. These responses are virtually identical to those shown in Figure 2, $C, D$, except that this neuron was excited by a contralateral decrease in EOD amplitude, whereas the neuron of Figure 2 was excited by contralateral increases in EOD amplitude. As mentioned earlier, both response types were seen in both the intra- and extracellular experiments. We also recorded these neurons' responses to long-term changes in EOD amplitude and they responded in a tonic fashion as described above. The responses seen with intracellular recording were sometimes less symmetrical than those seen extracellularly, that is, the tonic decreases in activity were relatively large but the increases were often smaller. This is probably also due to the fact that these cells were often somewhat depolarized and firing at abnormally high frequency.

A second type of NPd neuron, which projects to the EGP, was also recorded from intracellularly and its characteristics are summarized in Figure 10. This cell was fusiform in shape, and it had 2 major processes, one originating from each end of the cell. The cell body measured $8 \times 13 \mu \mathrm{m}$ and the dendritic arbors associated with each process were very asymmetrical. The process running laterally gave off relatively few branches and was much shorter than that projecting medially. The reconstruction of the medially directed process is incomplete and the figure underrepresents the volume of this dendrite's arbor. The axon was clearly visible and entered the PECB tract at the caudal boundary of the nucleus, where it branched and entered both the ipsilateral and contralateral PECB tract. The size of this neuron is similar to that of the other multipolars seen, but the morphology is different. This cell is similar in some respects to the tufted cell type described by Sas and Maler (1983). The terminal branches of the laterally oriented dendrite do form tuft-like structures; however, the size and appearance of the cell body are different from those described for tufted cells. This soma is smooth, but that of the tufted cell is described as rugose. The size of the tufted cell soma is given as about $8 \times 13 \mu \mathrm{m}$, which is exactly the same as our measurements of this cell; however, based on the comparisons of the size of our other cell types, including the stellate neurons to be described in the following report (Bratton and Bastian, 1990), our material must have experienced significant shrinkage. Hence, this neuron may be too large to be a tufted cell. Alternative possibilities are that this cell is an undescribed type of PECB projection neuron, or it may be one of the variants of the multipolar category.

The physiological characteristics of this neuron are similar to those of the multipolar cells. Spontaneous activity averaged 76 spikes/sec. It also responded to contralateral increases in EOD amplitude with decreased firing frequency (Fig. 10, $B, D$ ) and to contralateral EOD decreases with excitation (Fig. 10, $C, E$ ), and this cell responded tonically to prolonged changes in EOD amplitude. This cell did show a small difference in its response to the 100-msec contralateral EOD decrease. In the case of the typical multipolar cells, the initial excitatory response lasted 10 msec or less and was followed by a pause in the cell's firing (Figs. $2 C ; 9, C, E$ ). But this neuron showed no pause in activity following the excitatory burst (Fig. 10, $C, E$ ).

We have also recorded intracellularly from the axon terminals of high-frequency neurons within the EGP. The axons were less easily damaged; hence longer-duration recordings were possible. Exactly the same patterns of activity were seen in the EGP. Some neurons responded to contralateral increases in EOD amplitude with the short burst of activity, as shown in Figure 11, $A, C$, and with a pause in activity to the opposite stimulus polarity (Fig. 11, B, D), and others responded oppositely. Since the NPd projection is bilateral, we could not determine the location of the cell body from the physiological recordings and our best Lucifer yellow fills did not retrogradely fill cell bodies, although in some cases the axons could be traced to the caudallateral boundary of the NPd. The average spontaneous activity recorded from 4 of these NPd efferents averaged $77.7 \pm 15.6$ spikes/sec, a value much closer to that seen in the extracellular experiments. The tonic responses to prolonged changes in EOD amplitude were also seen with these EGP recordings. This neuron's average firing frequency of 119 spikes/sec (Fig. $11 F$ ) was increased to about 157 spikes/sec and decreased to 65.6 spikes/ sec due to a $9 \%$ increase and decrease in contralateral EOD amplitude, respectively (Fig. 11, $E, G$ ).

Reconstruction of the axonal arborization of this neuron and its location within the EGP is shown in Figure $11 H$. The axon enters the EGP from its lateral boundary and runs mediocaudally for a distance of about $300 \mu \mathrm{m}$. The axon gives off many small branches as it courses medially through the entire extent of the EGP and probably makes synaptic contact with large numbers of EGP granule cells. The branching pattern is not uniform; rather the branches form small domains. The extensive branching of these axons may explain the difficulty encountered in neuroanatomical experiments aimed at determining the mediolateral topography of the NPd projection to the EGP (Sas and Maler, 1987).

In addition to recording from cell bodies, we also often encountered axon terminals within the NPd. Recordings from 

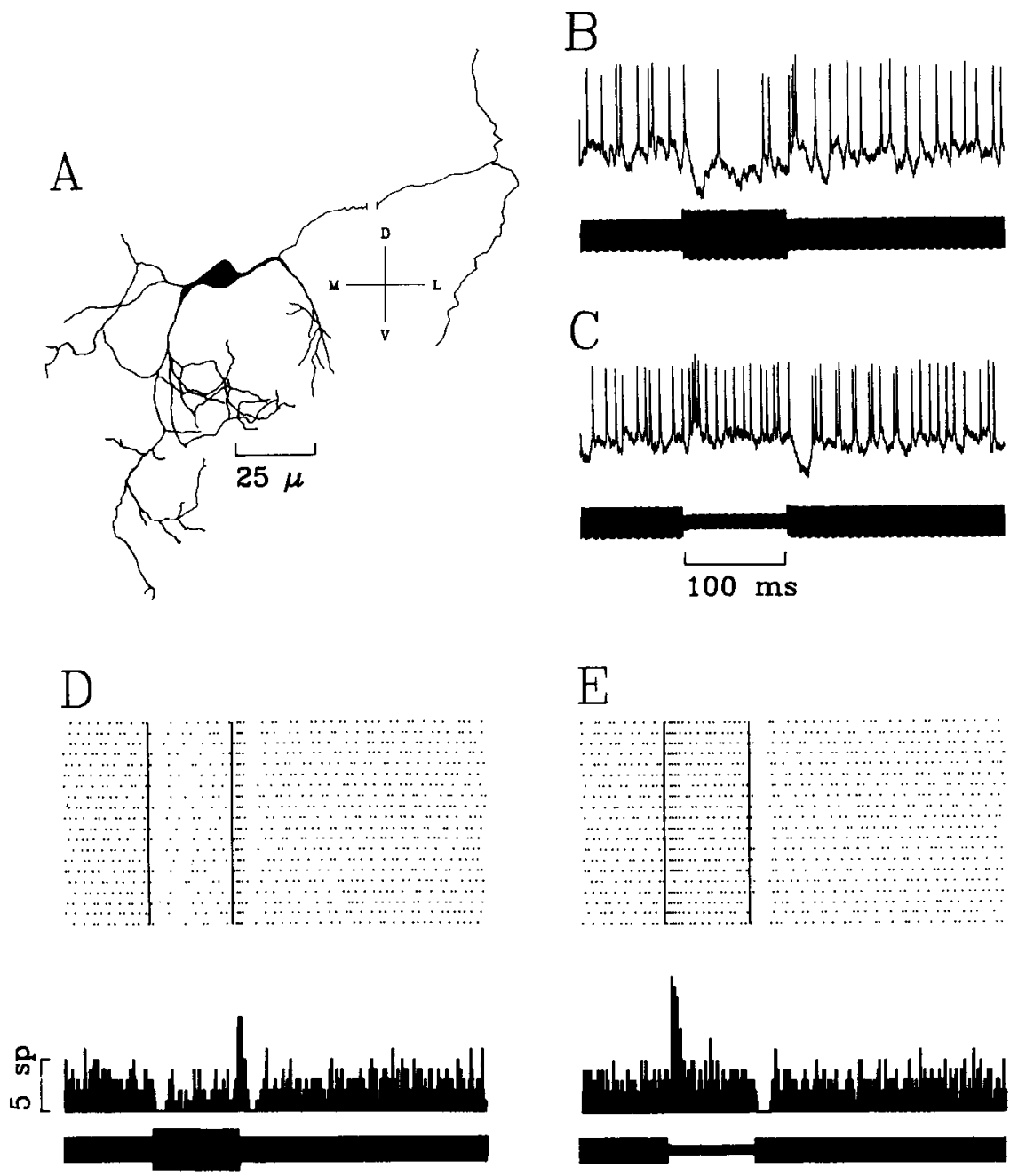

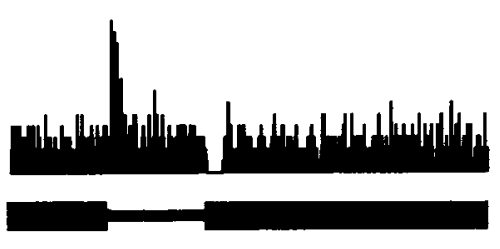

Figure 10. Anatomy and physiological properties of an NPd high-frequency neuron having physiological properties similar to those of multipolar cells. $A$, Reconstruction of Lucifer yellow fill; the axon can be seen leaving the nucleus laterally. $B, C$, Intracellular records of this neuron's responses to $0.375 \mathrm{mV} /$ $\mathrm{cm}$ rms increases and decreases in EOD amplitude. $D, E$, Raster displays and PSTHs of 20 responses to the stimuli of $B$ and $C$. these afferents were always typical "fiber recordings"; spikes originated from a flat baseline devoid of any indication of synaptic activity. The firing pattern of these units was more regular than that of the multipolar cells, bursts of 2 or more spikes were not seen, and the interval histograms of these units' spontaneous activity were usually bell shaped, as in Figure $2 B$. Spontaneous activity of 6 of these afferents averaged $54.9 \pm 6.0$ spikes $/ \mathrm{sec}$, a value significantly less than the average resting frequency of $72.3 \perp 4.95$ found for multipolar cells $(t$ test, $p=0.05)$. Thesc units also responded to prolonged changes in EOD amplitude with tonic changes in spike frequency. Lucifer yellow fills confirmed that the recordings were from NPd afferents, but the fills did not retrogradely label the cell bodies. These afferents terminated primarily in the caudal ventral region of the NPd, many large boutons were visible in well-filled cases, and the incoming axon could be traced for long distances within the lateral lemniscus toward the contralateral ELL. The identity of these NPd afferents remains unknown. Neuroanatomical studies indicate that these should be ELL output neurons. These cells, however, have much higher spontaneous rates than is typical for ELL basilar and nonbasilar pyramidal neurons (Bastian, 1981 b, 1986a, b; Shumway, 1989a), and their tonic response property has not been described for any type of ELL output neuron.

\section{Discussion}

Previous studies of the functional relationship between the NPd and the ELL have used microinjection of local anesthetics into the PECB or lesions of the PECB or of the posterior eminentia granularis to remove or reduce the activity in the descending pathway that influences the ELL indirectly. Striking changes in the physiological properties of the ELL output neurons that encode EOD amplitude result. The cells become less phasic and their responses to brief stepwise changes in EOD amplitude increase by about $300 \%$. Receptive field size for moving electrolocation targets also increases, as is expected given enhanced sensitivity to EOD distortions. ELL neurons' thresholds and $\mathrm{AM}$ frequency preferences are, however, not changed (Bastian, 1986a). The general effect of this treatment seems to be removal of a tonic inhibition of the ELL circuitry rendering the output elements more sensitive. Shumway and Maler (1989) have studied the effects of the GABA antagonist bicuculline microinjected into the pyramidal cell layer. Suppression of local GABAergic inhibition in this manner causes many of the same changes in ELL pyramidal cell physiology.

The idea that this descending tonic inhibition of ELL circuitry might be modulated in the normal fish in order to opti- 
Figure 11. Intracellular responses and anatomy of an NPd high-frequency efferent recorded within the EGP. $A, B$, Intracellular responses to $0.375 \mathrm{mV} / \mathrm{cm}$ rms increases and decreases in EOD amplitude. $C, D$, Raster displays and PSTHs of responses to 20 replicates of these stimuli. $E, G$, Interval histograms of this neuron's activity during $+9 \%$ and $-9 \%$ changes in EOD amplitude, respectively; $F$ shows spontaneous activity with the EOD at its normal value. $H$, Reconstruction of Lucifer yellow fill of this axon. The position of the axonal arborization within the EGP is shown in the left portion of the figure.
A

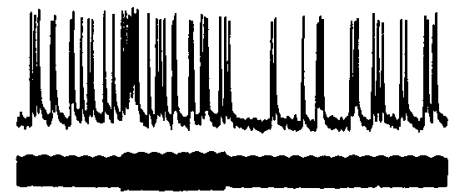

C

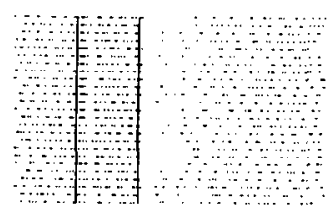

D
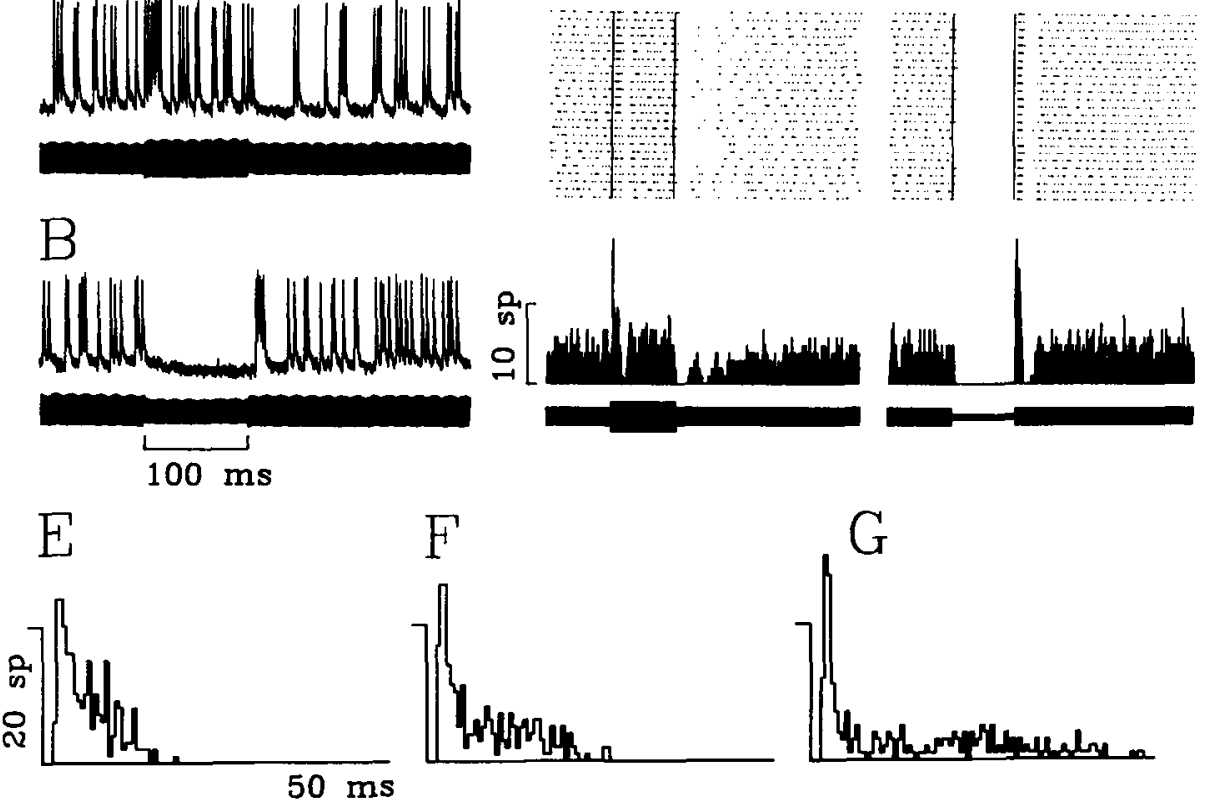

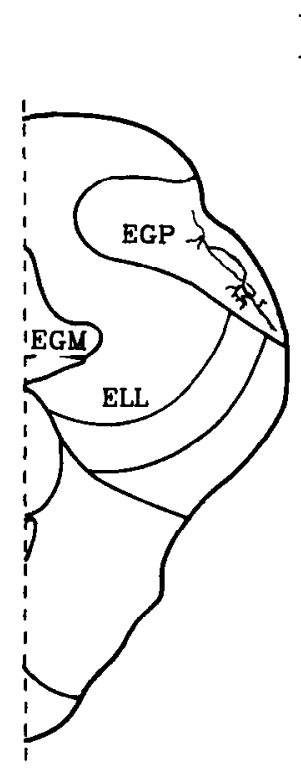

$\mathrm{H}$

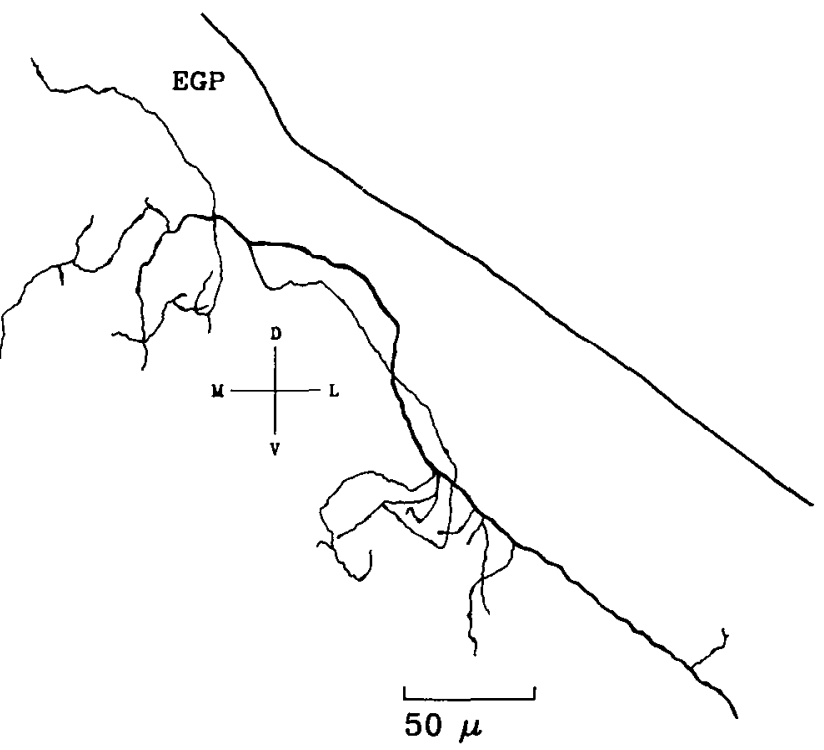

mize the sensitivity or gain of the ELL output neurons was tested by comparing the responses of single ELL basilar pyramidal cells (E-cells) to moving elcctrolocation targets before and after the EOD amplitude was altered in the same way as the prolonged changes in EOD amplitude were produced in this study (Bastian, $1986 \mathrm{~b})$. The change in transepidermal voltage resulting from a moving target and the ensuing change in electroreceptor input are functions of the amplitude of the electric organ discharge. ELL pyramidal neuron responses should vary with EOD amplitude unless some mechanism exists to compensate for the changes in the size of the object-caused EOD distortions. In normal fish, reductions of EOD amplitude as large as $50 \%$ caused no significant change in the responses of ELL basilar pyramidal neurons to moving targets. This stability of E-cell responses is dependent on an intact EGP (Bastian, 1986b). After lesions of this structure the ELL basilar pyramidal neurons' responses to moving targets decreased by from 30 to $50 \%$ in response to similar-sized reductions in EOD amplitude. These results indicate that, in the normal fish, the sensitivity of ELL output neurons can change, increasing in response to global decreases in the animal's EOD amplitude, and that this compensatory mechanism is dependent on an intact EGP. A similar constancy of ELL output neuron responses to moving targets distorting electric fields of different amplitudes was demonstrated in $E i$ genmannia, and this was also eliminated by bicuculline iontophoresis in the ELL pyramidal cell layer (Shumway and Maler, 1989).

An obvious requirement for a "gain control" mechanism capable of altering the sensitivity of ELL output neurons in such an adaptive manner is continuous information about the EOD 
amplitude. Changes in EOD amplitude must be measured and must somehow influence the ELL in order to bring about the appropriate change in output neuron sensitivity. Furthermore, it seems likely that the indirectly descending projection from the NPd is involved since anesthetic injected into the PECB tract or lesions of the EGP interfere with the gain control.

The NPd multipolar neurons are well suited for supplying this information. They encode EOD amplitude in a tonic fashion and with high sensitivity. The cells adopt a new, stable firing rate within about $1 \mathrm{sec}$ after the EOD amplitude is changed and the new rates remain stable for in excess of $4 \mathrm{~min}$, the longest times tested. The average change in spike frequency seen in the population studied was between 2 and 3 spikes/sec for a $1 \%$ change in EOD amplitude. The Lucifer yellow labeling confirms that the multipolar cells project via the PECB tract and the axonal recordings and labeling within the EGP show that these cells terminate within this structure. The earlier experiments in which this tract or the EGP itself was damaged certainly eliminated at least a portion of this descending information.

The multipolar neurons also responded to the other forms of electrosensory stimulation, and their responses to brief stepchanges in EOD amplitude, sinusoidal EOD AMs, and to moving electrolocation targets are somewhat similar to the responses of ELL output neurons. There are also differences which suggest that these NPd neurons are less well suited for processing spatially restricted EOD distortions such as result from moving electrolocation targets. These neurons respond well when the objects are close to the fish, but the responses decrease to the size of the spontaneous fluctuations in the cells' activity at distances of between 12.5 and $15 \mathrm{~mm}$ lateral to the fish. Electroreceptor afferents respond to this same sized target out to at least $20 \mathrm{~mm}$ lateral to the fish (Bastian, 1981 a), and, as is shown in Figure $7 A$, the average ELL basilar pyramidal cell responses are detectable out to about $25 \mathrm{~mm}$. The shorter range over which these NPd cells can detect objects and the small size of the responses relative to the cells' spontaneous rate of activity suggest that these neurons are specialized for some function other than detecting targets in the environment. It may be that the transient responses of these cells also provide important descending information to the EGP and ELL, but other NPd neurons, described in the following report (Bratton and Bastian, 1990), are far more sensitive to moving electrolocation targets and produce far stronger transient responses. They also project to the ELL; however, their projection is direct from the NPd to the ELL ventral molecular layer via the tractus stratum fibrosum.

The tonic nature of the multipolar neurons' responses to prolonged changes in EOD amplitude raises questions as to the source of their input. Ampullary receptors are an unlikely source of input to these NPd neurons since the multipolar cells do not respond to stimuli that drive the ampullary receptors. Tuberous electroreceptors respond in a phasic-tonic fashion to changes in EOD amplitude; hence, some information about the steadystate value of the EOD can be encoded by these afferents (Hagiwara et al., 1965; Scheich et al., 1973; Hopkins, 1976; Bastian, 1981a). However, the major afferent input to the NPd comes from the ELL or the torus semicircularis, and all of the ELL amplitude encoding output neurons described thus far are predominantly phasic in their responses (Enger and Szabo, 1965; Bastian, 1981 b, 1986a, b). More recent studies have shown some variability in the temporal response characteristics of ELL pyramidal cells contingent on the subdivision of the ELL recorded from (Shumway, 1989a), but no truly tonic responses have been described for ELL output neurons. The NPd afferents recorded from in this study have truly tonic response characteristics, enter the NPd from the lateral lemniscus, and can be traced toward the contralateral ELL. These are probably ELL output neurons, but it is not known yet whether these represent a subset of the ELL pyramidal cells specialized to provide this tonic information or whether these are axons of one of the relatively rare ELL cell types such as the multipolar or the ovoid neurons of the deep fiber lamina or the giant fusiform cells of the pyramidal cell layer (Maler, 1979). HRP injections into the NPd do occasionally label ovoid neurons (Maler et al., 1982). Further studies are planned to identify these neurons.

The results of this study suggest, but do not unequivocally demonstrate, that the multipolar cells receive inputs from both the ipsi- and contralateral ELLs. Electrolocation targets moved near to either side of the animal typically caused responses in these cells. This result must be interpreted with caution since ELL output neurons can also be weakly activated by targets moved along the contralateral side of the body. These ELL responses persist even when the electroreceptor input from the contralateral side is eliminated by severing the ganglion of the anterior lateral line nerve where it enters the brain (Bastian, $1986 a, c)$. These ELL responses are due to the contralateral target causing above-threshold distortions in the field received by the ipsilateral receptor population, and the NPd multipolar cell responses may be due to a similar effect.

The differences in the responses of the multipolar cells to prolonged changes in EOD amplitude presented with transverse versus symmetrical geometry, however, do suggest the presence of bilateral receptive fields. The transverse stimulus geometry was more effective in activating these neurons in 23 of 24 cases as compared to the symmetrical geometry and the 2 geometries were equally effective in one case. If receptive fields were restricted to one side of the body, then we would expect many of the neurons to show nearly equal responses to both stimulus geometries for a given change in transepidermal voltage. Exceptions to this prediction would occur in cases where the cell's receptive field included dorsal or ventral regions of the body surface. In these cases we would expect the transverse geometry to be less effective since the stimulus current flows tangential to the dorsal and ventral surfaces, resulting in smaller changes in transepidermal voltage relative to lateral regions of the fish. The symmetrical geometry causes uniform changes in EOD amplitude around the perimeter of the animal and would be expected to stimulate neurons with dorsal or ventral receptive fields more strongly. Stronger responses to symmetrical geometry were never seen.

The observation that the transverse geometry is more effective is easily explained if multipolar cells receive hilateral inputs, and if input from one side is predominantly excitatory while the other is inhibitory. Symmetrically presented stimuli would simultaneously increase the transepidermal voltage within the excitatory and inhibitory fields, resulting in a relatively low net excitatory input to the multipolar neuron. Transverse stimuli of one polarity, contralateral increase and ipsilateral decrease for example, would result in increased input to the excitatory region and decreased input to the inhibitory region. The opposite polarity would cause increased input to the inhibitory region and decreased input to the excitatory; hence the neurons would be significantly more responsive to the entire range of EOD changes tested. The existence of 2 subtypes of these neu- 
rons, those that respond with excitation to contralateral increases in EOD amplitude and those that increase activity with ipsilateral increases, is easily explained by assuming that the excitatory portion of the receptive field is located either contralateral or ipsilateral to the NPd studied.

The neuroanatomy shows that the projection from the ELL to the NPd does have a smaller ipsilateral component (Sas and Maler, 1983), and the studies of Tong (1982) showed that $17 \%$ of catfish NPd ncurons had bilateral receptive fields. Additional experiments are required to prove that multipolar cells receive bilateral inputs. The differences in the responses to symmetrical versus transversely applied stimuli, however, indicate that this is probably so. Further discussion of the multipolar neurons and a comparison of their properties with those of stellate neurons that project directly to the ELL ventral molecular layer are presented in the Discussion of the following paper (Bratton and Bastian, 1990).

\section{References}

Bastian, J. (1976) The range of electrolocation: A comparison of electroreceptor responses and the responses of cerebellar neurons in a gymnotid fish. J. Comp. Physiol. 108: 193-210.

Bastian, J. (1981a) Electrolocation. I. An analysis of the effects of moving objects and other electrical stimuli on the electroreceptor activity of Apteronotus albifrons. J. Comp. Physiol. 144: 465-479.

Bastian, J. (1981b) Electrolocation. II. The effects of moving objects and other electrical stimuli on the activities of two categories of posterior lateral line lobe cells in Apteronotus albifrons. J. Comp. Physiol. 144: $481-494$

Bastian, J. (1986a) Gain control in the electrosensory system mediated by descending inputs to the electrosensory lateral line lobe. J. Neurosci. 6: 553-562.

Bastian, J. (1986b) Gain control in the electrosensory system: A role for the descending projections to the electrosensory lateral line lobe. J. Comp. Physiol. 158: 505-515.

Bastian, J. (1986c) Electrolocation: Behavior, anatomy and physiology. In Electroreception, T. H. Bullock and W. Heiligenberg, eds., pp. 577-612, Wiley, New York.

Bratton, B., and J. Bastian (1990) Descending control of electroreception. II. Properties of nucleus praeeminentialis neurons projecting directly to the electrosensory lateral line lobe. J. Neurosci. 10:12411253.

Carr, C. E., and L. Maler (1986) Electroreception in gymnotiform fish: Central anatomy and physiology. In Electroreception, T. H. Bullock and W. Heiligenberg, eds., pp. 319-373, Wiley, New York.

Carr, C. E., L. Maler, and E. Sas (1982) Peripheral and central projections of the electrosensory nerves in gymnotiform fish. J. Comp. Neurol. 211: 139-153.

Enger, P. S., and T. Szabo (1965) Activity of central neurons involved in electroreception in some weakly electric fish (Gymnotidae). J. Neurophysiol. 28: 800-818.

Finger, T. E. (1986) Electroreception in catfish: Behavior, anatomy, and physiology. In Electroreception. T. H. Bullock and W. Heiligenberg, eds., pp. 287-317, Wiley, New York.

Frank, K., and M. C. Becker (1964) Microelectrodes for recording and stimulation. In Physical Techniques in Biological Research, Vol. 5 , part A, W. L. Nastuck, ed., pp. 23-84, Academic, New York.

Hagiwara, S., T. Szabo, and P. S. Enger (1965) Electroreceptor mech- anisms in a high-frequency weakly electric fish, Sternarchus albifons. J. Neurophysiol. 28: 784-799.

Heiligenberg, W. H., and J. Dye (1982) Labelling of electroreceptor afferents in a gymnotoid fish by intracellular injection of HRP: The mystery of multiple maps. J. Comp. Physiol, 148: 287-296.

Hopkins, C. D. (1976) Stimulus filtering and electroreception: Tuberous electroreceptors in three species of gymnotoid fish. J. Comp. Physiol. 111: 171-207.

Kalmijn, A. J. (1974) The detection of electric fields from inanimate and animate sources other than electric organs. In Handbook of Sensory Physiology, Vol. III/3, Electroreceptors and Other Specialized Receptors in Lower Vertebrates, A. Fessard, ed., pp. 147-200, Springer, New York.

Maler, L. (1979) The posterior lateral line lobe of certain gymnotoid fish: Quantitative light microscopy. J. Comp. Neurol. 183: 323-364.

Maler, L., T. Finger, and H. J. Karten (1974) Differential projections of ordinary lateral line receptors and electroreceptors in the gymnotid fish, Apteronotus (Sternarchus) albifrons. J. Comp. Neurol. 158: 363382.

Maler, L., E. K. B. Sas, and J. Rogers (1981) The cytology of the posterior lateral line lobe of high-frequency weakly electric fish (Gymnotidae): Dendritic differentiation and synaptic specificity in a simple cortex. J. Comp. Neurol. 195: 87-139.

Maler, L., E. Sas, C. Carr, and J. Matsubara (1982) Efferent projections of the posterior lateral line lobe in gymnotiform fish. J. Comp. Neurol 211: 154-164.

Mathieson, W. B., and L. Maler (1988) Morphological and electrophysiological properties of a novel in vitro preparation: The electrosensory lateral line lobe brain slice. J. Comp. Physiol. 163: 489-506.

Mathieson, W. B., W. Heiligenberg, and L. Maler (1987) Ultrastructural studies of physiologically identified electrosensory afferent synapses in the gymnotiform fish, Eigenmannia. J. Comp. Neurol. 255: 526-537.

Réthelyi, M., and T. Szabo (1973) Neurohistological analysis of the lateral line lobe in a weakly electric fish, Gymnotus carapo (Gymnotidae, Pisces). Exp. Brain Res. 18: 323-339.

Sas, E., and L. Maler (1983) The nucleus praeeminentialis: A Golgi study of a feedback center in the electrosensory system of gymnotid fish. J. Comp. Neurol. 221: 127-144.

Sas, E., and L. Maler (1987) The organization of afferent input to the caudal lobe of the cerebellum of the gymnotid fish Apteronotus leptorhynchus. Anat. Embryol. 177: 55-79.

Saunders, J., and J. Bastian (1984) The physiology and morphology of two types of electrosensory neurons in the weakly electric fish Apteronotus leptorhynchus. J. Comp. Physiol. 154: 199-209.

Scheich, H., T. H. Bullock, and R. H. Hamstra (1973) Coding properties of two classes of afferent nerve fibers: High frequency electroreceptors in the electric fish, Eigenmannia. J. Neurophysiol. 36: 3960.

Shumway, C. A. (1989a) Multiple electrosensory maps in the medulla of weakly electric gymnotiform fish. I. Physiological differences. J. Neurosci. 9: 4388-4399.

Shumway, C. A. (1989b) Multiple electrosensory maps in the medulla of weakly electric gymnotiform fish. II. Anatomical differences. J. Neurosci. 9: 4400-4415.

Shumway, C. A., and L. Maler (1989) GABAergic inhibition shapes temporal and spatial response properties of pyramidal cells in the electrosensory lateral line lobe of gymnotiform fish. J. Comp. Physiol. 164: 391-407.

Tong, S. L. (1982) The nucleus praeeminentialis: An electro- and mechanoreceptive center in the brainstem of the catfish. J. Comp. Physiol. 145: 299-309. 